\title{
Recent Advances in Telecommunications Avalanche Photodiodes
}

\author{
Joe C. Campbell, Fellow, IEEE
}

\begin{abstract}
For high-bit-rate long-haul fiber optic communications, the avalanche photodiode (APD) is frequently the photodetector of choice owing to its internal gain, which provides a sensitivity margin relative to PIN photodiodes. APDs can achieve 5-10-dB better sensitivity than PINs, provided that the multiplication noise is low and the gain-bandwidth product is sufficiently high. In the past decade, the performance of APDs for optical fiber communication systems has improved as a result of improvements in materials and the development of advanced device structures. This paper presents a brief review of APD fundamentals and describes some of the significant advances.
\end{abstract}

Index Terms-Avalanche photodiode, fiber optics, optical receiver, photodetector, photodiode.

\section{INTRODUCTION}

$\mathbf{O}$ VER THE past five decades, avalanche photodiodes (APDs) have been utilized for a wide range of commercial, military, and research applications. In recent years, the primary driving force for research and development of APDs has been the optical communications. It is well known that the internal gain of APDs provides a higher sensitivity in optical receivers than PIN photodiodes [1]-[4], however, at the cost of more complex epitaxial wafer structures and bias circuits. The APDs have been successfully deployed in optical receivers that operate up to $10 \mathrm{~Gb} / \mathrm{s}$, and research on materials and device structures that will extend to higher bit rate applications is ongoing.

First-generation optical fiber communication systems, which operated in the wavelength range from 800 to $900 \mathrm{~nm}$, utilized Si PIN and APDs [5]. The evolution of transmission wavelengths to 1300 and $1550 \mathrm{~nm}$, to take advantage of the optimum windows for low dispersion and attenuation, motivated a research on "long-wavelength" photodetectors. $\mathrm{In}_{0.53} \mathrm{Ga}_{0.47} \mathrm{As}$ (referred to henceforth as InGaAs) homojunctions quickly became the PIN photodiodes of choice, but at the high electric fields required for impact ionization, an excess dark current resulting from tunneling prevented their development as APDs [6], [7]. The tunneling component of the dark current was effectively eliminated with the development of separate absorption and multiplication (SAM) APD structures [8]. In these APDs,

Manuscript received July 4, 2006; revised October 12, 2006.

The author is with the Department of Electrical and Computer Engineering, School of Engineering and Applied Science, University of Virginia, Charlottesville, VA 22904-4743 USA (e-mail: jcc7s@virginia.edu; jccuva@ virginia.edu)

Color versions of one or more of the figures in this paper are available online at http://ieeexplore.ieee.org.

Digital Object Identifier 10.1109/JLT.2006.888481 the p-n junction and, thus, the high-field multiplication region are located in a wide bandgap semiconductor such as InP where the tunneling is insignificant and the absorption occurs in an adjacent InGaAs layer. By properly controlling the charge density in the multiplication layer, it is possible to maintain a high enough electric field to achieve a good avalanche gain while keeping the field low enough to minimize the tunneling and impact ionization in the InGaAs absorber. However, the frequency response of SAM APDs, as originally implemented, was very poor, owing to the accumulation of photogenerated holes at the absorption/multiplication heterojunction interface [9]. Several approaches to eliminate the slow release of trapped holes, including the use of a chirped-period $\mathrm{InP} / \mathrm{InGaAs}$ superlattice to form a pseudoquaternary $\operatorname{In}_{x} \mathrm{Ga}_{1-x} \mathrm{As}_{1-y} \mathrm{P}_{y}$ layer [10] and continuous grading of the transition region [11], have been reported. However, the approach that has been most widely adopted utilizes a transition region consisting of one or more latticed-matched intermediate-bandgap $\operatorname{In}_{x} \mathrm{Ga}_{1-x} \mathrm{As}_{1-y} \mathrm{P}_{y}$ layers [9], [12], [13]. A second modification to the original SAM APD structure has been the inclusion of a high-low doping profile in the multiplication region [14]-[16] similar to the reach-through structure that has been widely used for Si APDs [17]. In this structure, the wide-bandgap multiplication region consists of a lightly doped (usually unintentionally doped) layer where the field is high, and an adjacent doped charge layer or field control region. This type of APD, which is frequently referred to as the SACM structure with the "C" representing the charge layer, decouples the thickness of the multiplication region from the charge density constraint in the SAM APD.

Most of the initial work on InP/InGaAsP/InGaAs SAM and SACM APDs utilized mesa structures because of their fabrication simplicity and reproducibility. However, the consensus that planar structures are more reliable than mesa-type photodiodes spurred the development of planar configurations. Some of the techniques that have been successfully demonstrated utilize a lateral extended guard ring [18]-[20], floating guard rings [21]-[24], pre-etched charge sheet with regrowth [25], etched diffusion well [26], or selective ion implantation of the charge region [15]. Each of these approaches has been successful in suppressing an edge breakdown. Fig. 1 shows a schematic cross section of an InP/InGaAsP/InGaAs SACM APD with a double diffused floating guard ring [22]. The adjacent graph shows the electric field profile normal to the surface and illustrates how the charge layer is used to tailor the relative fields in the multiplication and absorption layers.

While the InP/InGaAsP/InGaAs SACM APDs have achieved excellent receiver sensitivities up to $2.5 \mathrm{~Gb} / \mathrm{s}$ [27]-[29], there are three factors that limit their performance at higher bit 


\begin{tabular}{|c|c|}
\hline InGaAs, Contact, $\mathrm{p}^{+}>9 \times 10^{18}, 30 \mathrm{~nm}$ & \multirow{4}{*}{$\begin{array}{l}420 \mathrm{~nm} \text { absorptior } \\
\text { layer }\end{array}$} \\
\hline InAlAs, $\mathrm{p}^{+}, 4 \mathrm{X10^{18 } , 5 0 0 \mathrm { nm }}$ & \\
\hline InGaAs, Be, $1.0 \times 10^{16}, 270 \mathrm{~nm}$ & \\
\hline InGaAs, Be, $4.0 \times 10^{16}, 150 \mathrm{~nm}$ & \\
\hline InGaAlAs, $1.0 \times 10^{16}, 50 \mathrm{~nm}$ & \multirow{9}{*}{$\begin{array}{l}I^{2} \mathbf{E} \text { multiplication } \\
\text { region }\end{array}$} \\
\hline InAlAs, p, $2.2 \times 10^{17}, 80 \mathrm{~nm}$ & \\
\hline InGaAlAs, Q1.1, p, $2.2 \times 10^{17}, 120 \mathrm{~nm}$ & \\
\hline InGaAlAs, Q1.1, un-doped, 80nm & \\
\hline In AlAs, un-doped, 80nm & \\
\hline$n+:$ InAIAs, $5 \times 10^{18}, 500 \mathrm{~nm}$ & \\
\hline$n+:$ InAIAs, buffer, $500 \mathrm{~nm}$ & \\
\hline i: InAlAs, buffer, $100 \mathrm{~nm}$ & \\
\hline SI: InP substrate & \\
\hline
\end{tabular}

Fig. 1. Schematic cross section of InP/InGaAsP/InGaAs SACM APD with double-diffused floating guard ring configuration [22].

rates. Since they operate under a normal incidence, and since the absorption coefficient of InGaAs at telecommunications wavelengths is $\sim 10^{4} \mathrm{~cm}^{-1}$ [30], [31], the absorption region must be approximately $2.5-\mu \mathrm{m}$ thick in order to absorb $>90 \%$ of the light that enters the detector. The associated transit times limit the bandwidth to $10 \mathrm{GHz}$ at low gain. At higher gains, the relatively low gain-bandwidth product $(<100 \mathrm{GHz})$ restricts the frequency response. As will be discussed below, the gainbandwidth product and the high excess noise are consequences of the reasonably unfavorable ionization coefficients of InP [32], [33]. Much of the recent work on APDs has focused on developing new structures and incorporating alternative materials that will yield lower noise and higher speed while maintaining optimal gain levels.

The multiplication region of an APD plays a critical role in determining its performance, specifically the gain, the multiplication noise, and the gain-bandwidth product. According to McIntyre's local-field avalanche theory [34]-[36], both the noise and the gain-bandwidth product of APDs are determined by the electron $\alpha$ and hole $\beta$ ionization coefficients of the semiconductor in the multiplication region, or more specifically, their ratio $k=\beta / \alpha$. The noise power spectral density $\phi$ for mean gain $\langle M\rangle$ and mean photocurrent $\left\langle I_{\mathrm{ph}}\right\rangle$ is given by the expression $\phi=2 q\left\langle I_{\mathrm{ph}}\right\rangle\langle M\rangle^{2} F(M) . F(M)$ is the excess noise factor, which arises from the random nature of impact ionization. Under the conditions of uniform electric fields and pure electron injection, the excess noise factor is

$$
\begin{aligned}
F(M) & =\left\langle M^{2}\right\rangle /\langle M\rangle^{2} \\
& =k\langle M\rangle+(1-k)(2-1 /\langle M\rangle) .
\end{aligned}
$$

Equation (1) has been derived under the condition that the ionization coefficients are in local equilibrium with the electric field, hence, the designation "local field" model. This model assumes that the ionization coefficients at a specific position are determined solely by the electric field at that position. It is well known that the impact ionization is nonlocal, in that, carriers injected into the high-field region are "cool" and require a certain

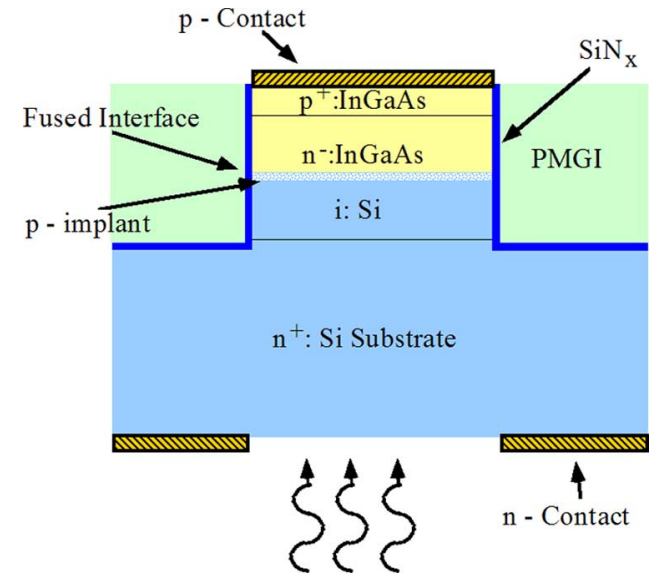

Fig. 2. Schematic cross section of wafer-bonded Si/InGaAs heterojunction APD [46].

distance to attain a sufficient energy to ionize [37]. This also applies to carriers immediately after the ionization, because their final states are typically near the band edge. The distance in which essentially no impact ionization occurs is frequently referred to as the "dead space" $d_{\mathrm{e}(\mathrm{h})}$ for electrons (holes). If the multiplication region is thick, the dead space can be neglected, and the local field model provides an accurate description of the APD characteristics. It is clear from (1) that the lower noise is achieved when $k=1$. The gain-bandwidth product results from the time required for the avalanche process to build up or decay: The higher the gain, the higher the associated time constant and, thus, the lower the bandwidth. Emmons [38] has shown that the frequency-dependent gain can be approximated by the expression $M(\omega)=M_{\mathrm{o}} / \sqrt{1+\left(\omega M_{\mathrm{o}} k \tau\right)^{2}}$, where $M_{\mathrm{o}}$ is the dc gain, and $\tau$ is approximately (within a factor of $\sim 2$ ) the carrier transit time across the multiplication region. It follows from this expression that for $M_{\mathrm{o}}>\alpha / \beta$, the frequency response is characterized by a constant gain-bandwidth product that increases as $k$ decreases.

There are three documented methods to achieve a low excess noise in an APD. The best known approach is to select materials such as $\mathrm{Si}$ [39]-[42] or $\mathrm{Hg}_{0.7} \mathrm{Cd}_{0.3} \mathrm{Te}$ [43], [44] that have $k=1$. The low-noise characteristics of $\mathrm{Si}$ are well documented; however, Si photodiodes do not operate at the telecommunications wavelengths because the bandgap of $\mathrm{Si}$ is transparent at 1300 and $1550 \mathrm{~nm} . \mathrm{Hg}_{0.7} \mathrm{Cd}_{0.3} \mathrm{Te}$, which has a long-wavelength cutoff of $\sim 4.3 \mu \mathrm{m}$, has achieved the lowest excess noise reported to date, $k \approx 0$ [44]. The low noise appears to result from novel aspects of the bandstructure; the effective mass ratio $\left(m_{\mathrm{h}} / m_{\mathrm{e}} \sim 30\right)$ is very large, and unlike most III-V semiconductors, $\mathrm{Hg}_{0.7} \mathrm{Cd}_{0.3} \mathrm{Te}$ has a very small bandgap $(0.25 \mathrm{eV})$ for the $\Gamma$ valley, and very high $L$ and $X$ valleys (1.5 and $2.5 \mathrm{eV}$, respectively) [45]. On the other hand, the small bandgap of $\mathrm{Hg}_{0.7} \mathrm{Cd}_{0.3} \mathrm{Te}$ necessitates cooling in order to reduce the dark current. It will be interesting to see if these low-noise characteristics can be extended to higher bandgap (shorter operating wavelength) compositions that operate at room temperature.

An intriguing device structure (Fig. 2) that takes advantage of the excellent noise characteristics of $\mathrm{Si}$ while attaining a response to $\sim 1.6 \mu \mathrm{m}$ involves wafer bonding of a narrow 


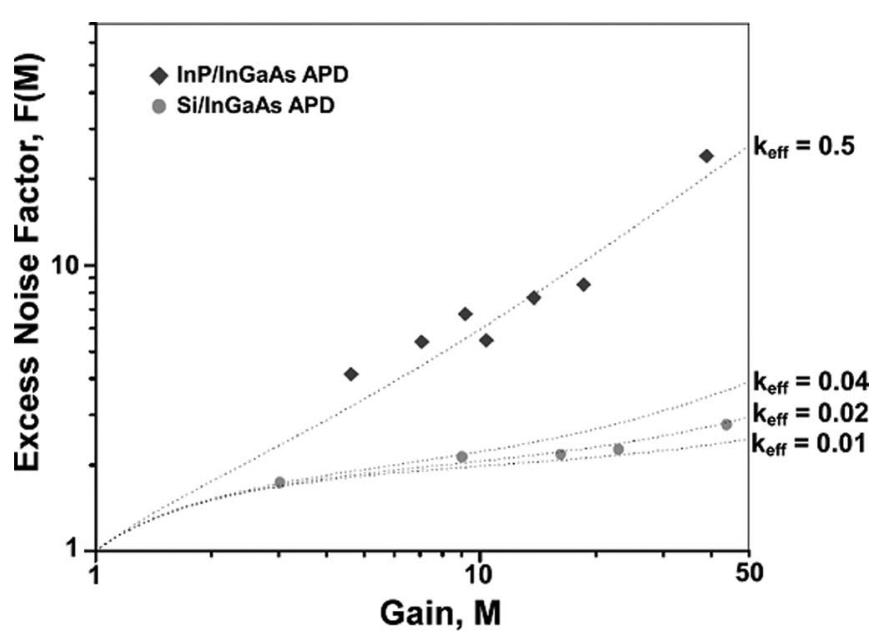

Fig. 3. Excess noise factor $F(M)$ for wafer-bonded $\mathrm{Si} / \mathrm{InGaAs}$ heterojunction APD. Excess noise for an InP APD is shown for comparison [48].

bandgap absorber such as $\operatorname{In}_{0.53} \mathrm{Ga}_{0.47}$ As to a Si multiplication region [46]-[48]. This approach is also attractive because $\mathrm{Si}$ APDs have achieved very high gain-bandwidth products, and the breakdown voltage exhibits a temperature dependence of only $0.026 \mathrm{~V} /{ }^{\circ} \mathrm{C}$ [48] compared to $0.15 \mathrm{~V} /{ }^{\circ} \mathrm{C}$ for InP APDs. $\mathrm{Si} / \mathrm{InGaAs}$ heterojunction APDs have achieved low dark current $\left(4 \times 10^{-5} \mathrm{~A} / \mathrm{cm}^{2} @ M=50\right)$ [48], excess noise levels (Fig. 3) comparable to Si homojunction devices $(\mathrm{k} \sim 0.02)$ [47], [48], and bandwidths up to $4.8 \mathrm{GHz}$ [48]. However, a commercial production of $10-\mathrm{Gb} / \mathrm{s}$ APDs has yet to be achieved because of the material issues related to the bonded interface between InGaAs and Si.

A variant of this approach is the solid-state impact-ionization multiplier (SIM), in which the photocurrent from an arbitrary photodiode is amplified by an impact ionization in Si [49]-[51]. To date, two variants have been reported. One configuration, as shown in Fig. 4(a), consists of a Si Schottky barrier on a $\mathrm{p}^{-}$epitaxial layer with an implanted $\mathrm{n}^{+}$region to collect primary and secondary electrons. The other SIM, a surface structure [Fig. 4(b)], is fabricated on an n-type substrate and has implanted $\mathrm{p}$ regions adjacent to the Schottky barrier. The operation of both implementations is similar. A current is injected into the Schottky barrier from an external current source, typically a PIN photodiode. The bias between the $\mathrm{n}^{+}$contact and the Schottky barrier creates a high-field region in which a gain is achieved by an impact ionization of electrons. Without the lateral p-type electrodes [substrate contact in Fig. 4(a) and "p-sink" in Fig. 4(b)], the secondary holes would recombine with incoming primary electrons and quench the avalanche gain. Advantages of the SIM include the following: 1) The photodetector and the amplification functions can be optimized separately without the constraint of materials compatibility; 2) small-element large-area arrays can be fabricated using the conventional VLSI process technology; and 3) amplifier stages can be cascaded to achieve a net noise reduction. One performance metric is gain efficiency, the product of the injection efficiency, and the current gain. Fig. 5 shows the gain efficiency of a SIM similar to that in Fig. 4(a), with a photocurrent injected from an external InGaAs PIN photodiode. Since the SIM input can be an arbitrary current source, SIM stages can

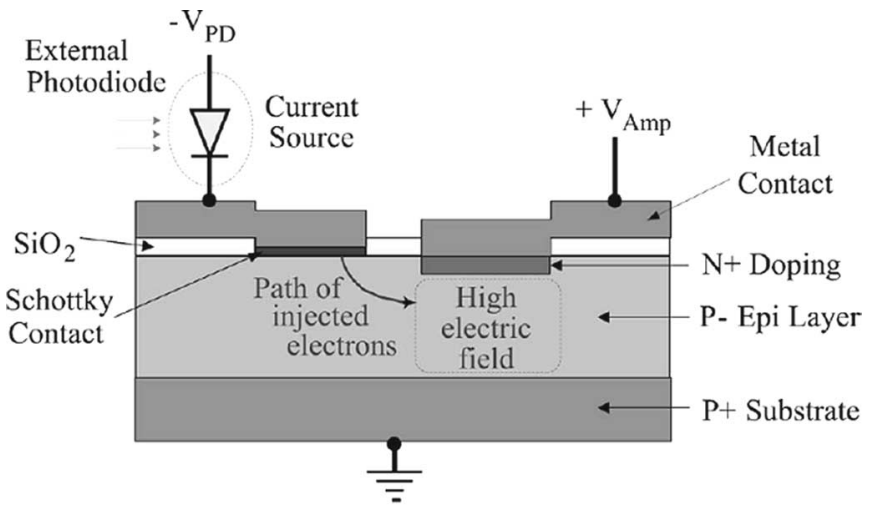

(a)

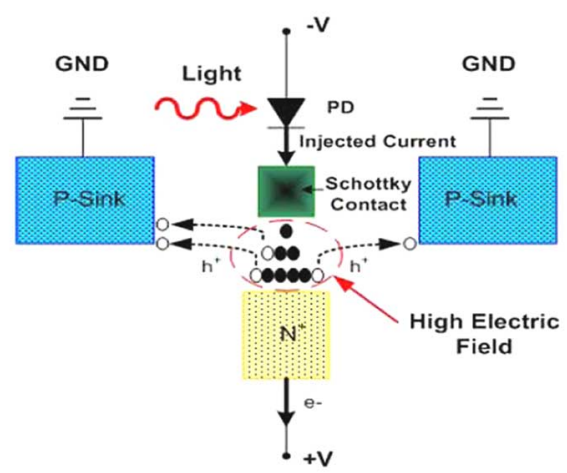

(b)

Fig. 4. (a) Solid-state impact ionization multiplier with substrate p contact [51] and (b) surface structure with ion-implanted "p sink" regions [50].

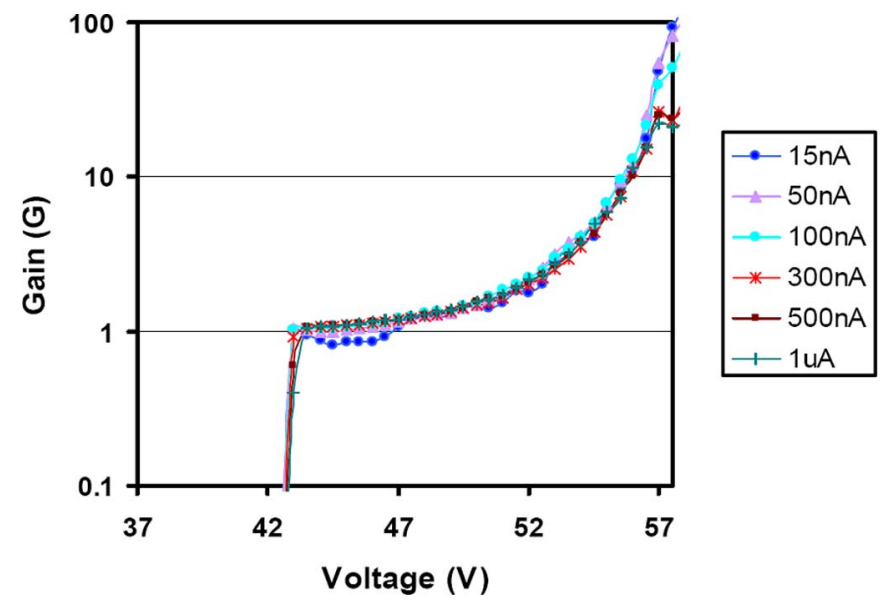

Fig. 5. Gain efficiency versus applied voltage for device in Fig. 4(b) [50].

be cascaded. The benefit of cascading can be deduced from (1). The noise power divided by the signal gain increases with gain. It follows that two cascaded amplifiers, each with gain $M$, have the same gain but less noise compared to a single stage with gain $M$ [2], [51].

Low excess noise and high gain-bandwidth product have also been achieved by a submicrometer scaling of the thickness of the multiplication region $w_{m}$. This is somewhat counterintuitive since it appears to contradict the local field model. As $w_{m}$ is reduced, in order to maintain the same gain, the electric field intensity must increase in order to reduce the distance between ionization events. However, for high electric fields, the 


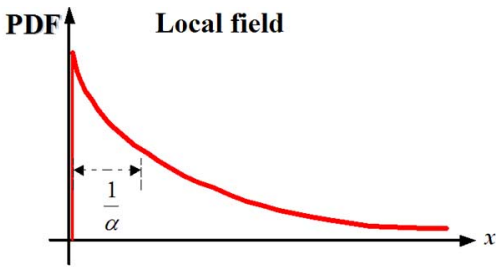

(a)

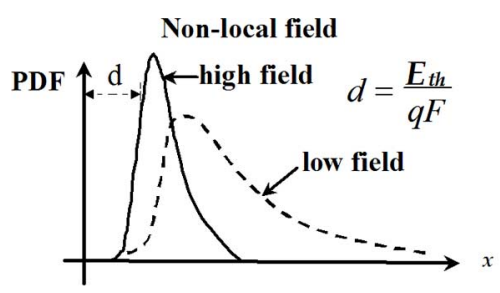

(b)

Fig. 6. PDFs for (a) the local field model and (b) inclusion of the dead space for high field (solid line) and low field (dashed line).

electron and hole ionization coefficients tend to merge so that $k$ approaches unity. Consequently, based on the excess noise expression in (1), a higher excess noise would be expected for the same gain. We recall, however, that the local field model is only valid when the dead space can be ignored, which proves not to be the case for thin multiplication regions. The importance of the nonlocal nature of the impact ionization, as manifested in the "dead space," in reducing the excess noise can be explained as follows: Since the impact ionization is a stochastic process, it can best be described in terms of the probability distribution function (pdf) $p(x)$, which is the probability per unit length that a carrier ionizes a distance $x$ from the injection point or the point where it was created by another impact ionization event. For the local field theory, as shown in Fig. 6(a), the pdf for electrons has the form $p_{\mathrm{e}}(x)=\alpha^{-1} \exp (-\alpha x)$. At the high fields encountered in the thin multiplication regions, the pdf must be modified to account for the fact that $p(x) \sim 0$ for $x<$ the dead space. Several analytical [52]-[56] and numerical models [57]-[59] have successfully been developed to accurately include the effect of the dead space. Although differing markedly in their approach, the physical picture that emerges from these models is consistent and matches up well with the experimental measurements. Fig. 6(b) illustrates qualitatively how incorporating the dead space alters the pdfs. First, we observe that the dead space length decreases with an increasing field. As carriers transit the multiplication region, they continuously gain energy from the electric field and lose energy by an optical phonon scattering. At the highest fields, the phonon scattering becomes less significant because the phonon energy is small, a few tens of microelectronvolts. As a result, the carrier transport becomes "quasi-ballistic," and the dead space length is, to good approximation, equal to $E_{\mathrm{th}} / q F$, where $E_{\mathrm{th}}$ is the threshold energy for impact ionization, $q$ is the electron charge, and $F$ is the electric field strength. The decrease in dead space length with an increasing field tends to make it less significant at high fields. However, we note that the pdf also narrows significantly with the increasing field. Since the width of the pdf decreases faster than the contraction in the dead space, the net result is

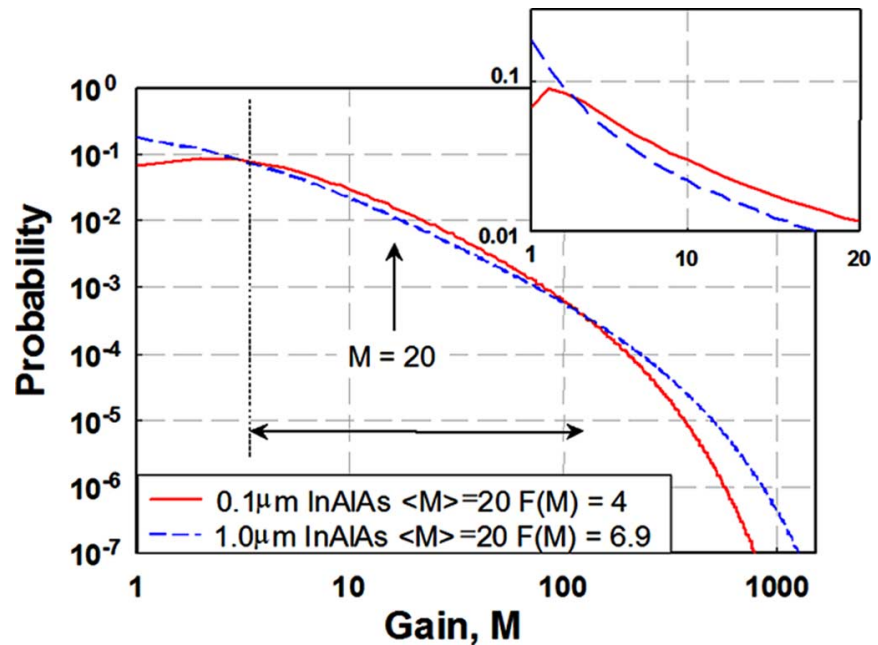

Fig. 7. Comparison of the gain distribution curves for $\mathrm{Al}_{0.48} \mathrm{In}_{0.52} \mathrm{As} \mathrm{APDs}$ having multiplication region widths of $1.0 \mu \mathrm{m}$ (dashed line) and $0.1 \mu \mathrm{m}$ (solid line). The average gain for both APDs is $M \sim 20$, but the excess noise factors for the 1.0- and 0.1- $\mu \mathrm{m}$ APDs are 6.9 and 4, respectively [60].

that the ionization process becomes more deterministic which reduces the variation in $M$. Fig. 7 shows the calculated gain distributions for two $\mathrm{Al}_{0.48} \mathrm{In}_{0.52}$ As APDs with multiplication layer thickness of $1.0 \mu \mathrm{m}$ (dashed line) and $0.1 \mu \mathrm{m}$ (solid line) [60]. These APDs have the same average gain, $M \sim 20$, but the excess noise factors are 6.9 and 4.0 for the 1.0 and $0.1 \mu \mathrm{m}$ APDs, respectively. The gain distribution of the $1.0-\mu \mathrm{m}$ APD is broader than that of the $0.1-\mu \mathrm{m}$ device, which gives rise to higher excess noise. This graph also shows that the thicker device has higher probabilities for both high gain $(M>100)$ and low gain $(M=1)$, while the probabilities for the thin device are higher for gains in the range $2<M<100$. This is reasonable since they have different standard deviations in $M$ while keeping $\langle M\rangle$ the same. It is interesting to note that the $1.0-\mu \mathrm{m}$ APD has a peak at $M=1$, while the $0.1-\mu \mathrm{m}$ APD has a peak at $M=2$. This is consistent with the pdfs in Fig. 6. The long tail in the distribution at low field, which is a characteristic of thick multiplication regions, is indicative of a greater probability that a carrier will travel a longer distance, which in some cases can be the whole multiplication region, before ionizing. This has also been observed in [58].

Noise reduction in thin APDs has been demonstrated for a wide range of materials, including $\mathrm{InP}$ [61]-[64], GaAs [58], [63]-[68], $\mathrm{Al}_{x} \mathrm{In}_{1-x} \mathrm{As}$ [63], [64], [69], $\mathrm{Si}$ [70], [71], $\mathrm{Al}_{x} \mathrm{Ga}_{1-x} \mathrm{As}$ [63], [64], [72]-[75], SiC [76], GaP [77], and GaInP [78]. Fig. 8 shows the excess noise figure versus the gain for GaAs APDs with $w_{m}$ in the range from 0.1 to $0.8 \mu \mathrm{m}$ [54]. The dashed lines are plots of (1) for $k=0.2$ to 0.5 . These lines are not representative of the actual $k$ values; they are presented solely for reference because the $k$ value has become a widely used indirect figure of merit for excess noise. For constant gain, it is clear that the excess noise falls significantly with a decreasing $w_{m}$.

While shrinking the multiplication region thickness is an effective approach to noise reduction, it should be noted that this is relative to the characteristic noise of the bulk (thick) material. Thus, it appears that lower noise can be 


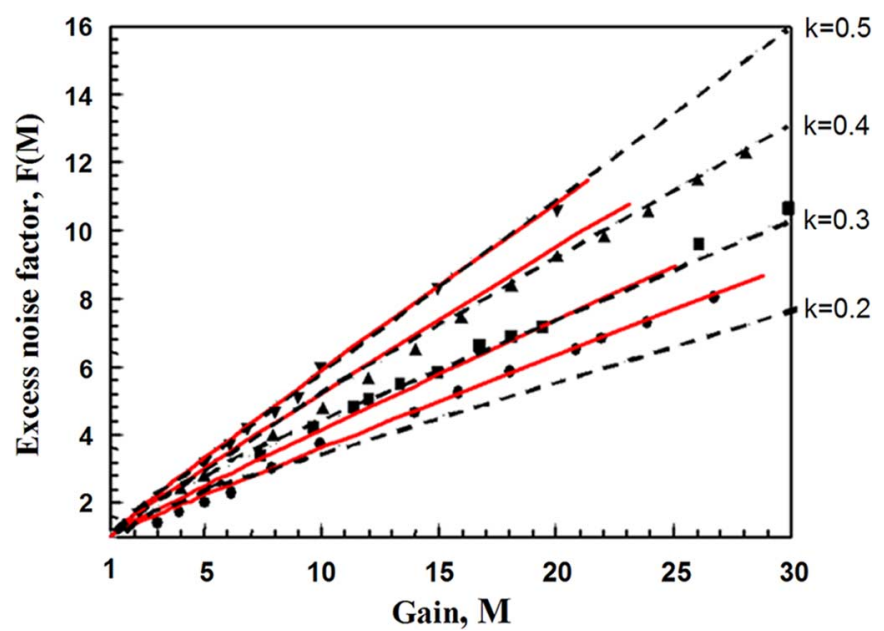

Fig. 8. Comparison of the calculated noise curves (solid lines) with experimental data for GaAs homojunction APD of different thickness $0.1(\star)$, $0.2(\square), 0.5(\pi)$, and $0.8 \mu \mathrm{m}(\theta)$.

achieved by beginning with "low-noise" semiconductors. For this reason, $\mathrm{In}_{0.52} \mathrm{Al}_{0.48} \mathrm{As}$ is an attractive candidate to replace InP in telecommunications APDs. Like $\operatorname{In}_{0.53} \mathrm{Ga}_{0.47} \mathrm{As}$, $\mathrm{In}_{0.52} \mathrm{Al}_{0.48} \mathrm{As}$ (referred to below as InAlAs) can be grown lattice-matched on InP substrates. Watanabe et al. [79] have measured the ionization coefficients for InAlAs and found that $\beta / \alpha \sim 0.3$ to 0.4 for electric field in the range from 400 to $650 \mathrm{kV} / \mathrm{cm}$, which compares favorably with $\alpha / \beta \sim 0.4$ to 0.5 for InP. Lenox et al. [69] investigated the excess noise characteristics of PIN-structure InAlAs APDs; the excess noise was equivalent to $k=0.2$ and 0.31 for $w_{m}=200$ and $1600 \mathrm{~nm}$, respectively. Thin layers of AlInAs have also been incorporated into the multiplication region of SACM APDs. A resonantcavity InGaAs/InAlAs SACM APD operating at wavelength of $1.55 \mu \mathrm{m}$ achieved $70 \%$ external quantum efficiency, $24-\mathrm{GHz}$ unity gain bandwidth, excess noise equivalent to $k \sim 0.18$, and 290-GHz gain-bandwidth product [80]. Li et al. [81] reported that the undepleted-absorber InAlAs APDs with 180-nmthick multiplication regions exhibited an excess noise equivalent to $k=0.15$ and gain-bandwidth product of $160 \mathrm{GHz}$. InGaAs/InAlAs SACM APDs with thin multiplication layers have also been used to fabricate a $40 \times 40$ imaging array [82]. Fig. 9 shows a pass-fail map and a histogram of dark current for the 1600 elements of the array. The average dark current at a gain of ten was $1.66 \mathrm{nA}$, with a standard deviation of only $0.17 \mathrm{nA}$, i.e., $\sim 10 \%$. The gain was also very uniform with a similar deviation. This type of array does not have a direct bearing on fiber optic transmission systems, but the results do provide a good indication of material quality and uniformity, which is germane to manufacturing yield of discrete devices. The APDs reported in [80]-[82] were mesa structures. Several planar InAlAs/InGaAs SACM APDs have also been developed. This has been more challenging than fabricating planar InP/InGaAs SACM APDs owing to the absence of a good n-type diffusant coupled with the requirement for electron injection. Watanabe et al. [83], [84] developed a quasi-planar structure, with InAIGaAs-InAlAs multiple quantum well multiplication region and Ti-implanted guard ring. These APDs exhibited a dark current of $0.36 \mu \mathrm{A}$ at a gain of ten, an external quantum efficiency of $67 \%$, a $110-\mathrm{GHz}$ gain-bandwidth product, and a low gain bandwidth of $15 \mathrm{GHz}$. Deployment of these APDs, however, has been limited by the difficulties in optimizing $\mathrm{Ti}$ ion dosage and the Ti-activation anneal and the relatively high dark current [85]. Recently, an AlInAs/InGaAs planar SACM APD without a guard ring has been reported [85], [86]. Fig. 10 shows a schematic cross section. The active region is defined by a $\mathrm{Zn}$ diffusion through a transparent InP window layer to the InGaAs absorption region. In this case, the $\mathrm{p}-\mathrm{n}$ junction and, thus, the high-field region are located below the diffusion front at the interface between the p-type InAlAs charge layer and the thin $(200 \mathrm{~nm})$ unintentionally doped InAlAs multiplication region. These APDs have achieved a gain of $>40$, high external quantum efficiency $(88 \%), 10-\mathrm{GHz}$ low gain bandwidth, and gain-bandwidth product of $120 \mathrm{GHz}$.

The noise characteristics of $\mathrm{Al}_{x} \mathrm{Ga}_{1-x}$ As for $x=0$ to 0.9 have been studied for bulk and thin multiplication layers [72], [73], [87]-[91]. Plots of the excess noise of $\mathrm{Al}_{x} \mathrm{Ga}_{1-x} \mathrm{As} \mathrm{p}^{+}$in $^{+}$ for $x$ in the range from 0.4 to 0.9 are shown in Fig. 11 [89]. The multiplication layer thickness for these measurements was between 0.8 and $1.1 \mu \mathrm{m}$. The excess noise decreases with an increasing $\mathrm{Al}$ content; very low noise corresponding to $k<0.2$ is observed for $x \leq 0.8$ even for a multiplication thickness of $\sim 1 \mu \mathrm{m}$. Ng et al. [89] have attributed this to a decrease in the hole ionization coefficient. Even lower excess noise (equivalent to $k<0.1$ ) has been achieved by reducing the multiplication length to take advantage of the nonlocal effect [89], [90]. The combination of low noise, wide bandgap to suppress tunneling, and lattice match to GaAs make $\mathrm{Al}_{x} \mathrm{Ga}_{1-x} \mathrm{As}$ an attractive candidate for high-performance APDs. However, more research is required to incorporate an absorption region that can extend operation to telecommunications wavelength. One approach is to utilize $\operatorname{GaInAs}(\mathrm{N})$, which has been widely studied for "Alfree" lasers. A concern for this approach is the lattice mismatch between $\operatorname{GaAs}(\mathrm{N})$ and $\mathrm{Al}_{x} \mathrm{Ga}_{1-x} \mathrm{As}$, which makes it difficult to obtain sufficiently thick absorbing layers to achieve acceptable responsivity. One approach to circumvent this difficulty would be to utilize the thin absorbing layers in a resonant-cavity structure [92].

Recently, it has been shown that the noise of APDs with thin multiplication regions can be reduced even further by incorporating new materials and impact ionization engineering $\left(I^{2} E\right)$ with appropriately designed heterostructures [93]-[100]. Structurally, $I^{2} E$ is similar to a truncated multiple quantum well (frequently mislabeled as "superlattice") APD [101], [102]; however, operationally, there is a fundamental difference, in that, these APDs do not invoke heterojunction band discontinuities. The structures that have achieved the lowest excess noise, to date, utilize the multiplication regions in which electrons are injected from a wide bandgap semiconductor into an adjacent low bandgap material. Initial work that demonstrated the efficacy of this approach utilized the $\mathrm{GaAs} / \mathrm{Al}_{x} \mathrm{Ga}_{1-x} \mathrm{As}$ material system [93], [94], [96]-[98]. Excess noise equivalent to $k<0.1$ has been demonstrated [96], [97]. Recently, InGaAlAs/InP implementations that operate at the telecommunications wavelengths have been reported. Using both a single-well structure and a pseudograded bandgap based 


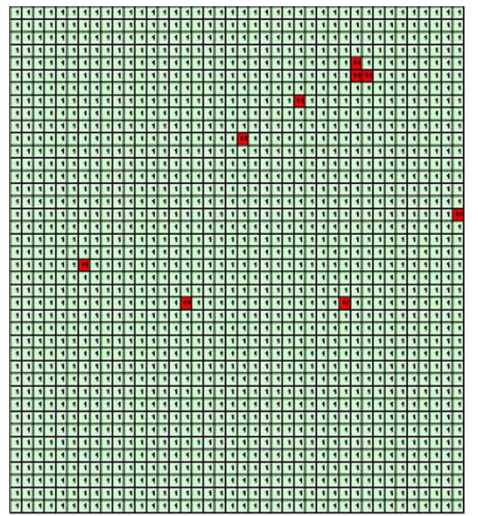

(a)

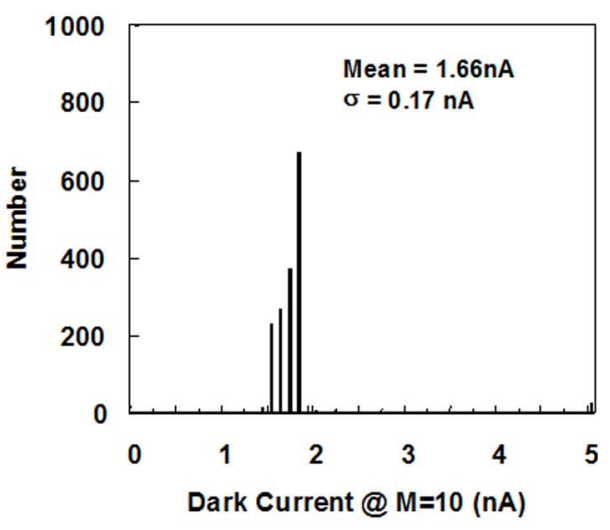

(b)

Fig. 9. (a) Pass/fail map of a $40 \times 40$ AlInAs/InGaAs APD array with $>99 \%$ yield and (b) histogram of the dark current at a gain of ten of the 1600 elements of the array [82].

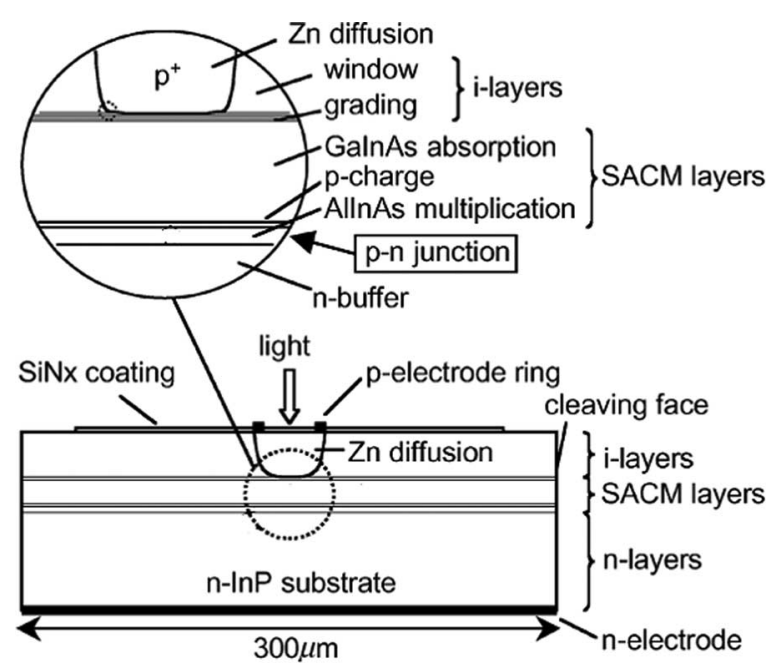

Fig. 10. Schematic cross section of AlInAs/InGaAs planar SACM APD without a guard ring [86].

on InAlAs/InGaAlAs materials, Wang et al. [99] demonstrated an excess noise equivalent to $k \sim 0.12$ and a dark current comparable to that of homojunction InAlAs APDs. Duan et al. have incorporated a similar $I^{2} E$ multiplication region into a Molecular Beam Epitaxy (MBE) grown InGaAlAs $I^{2} E$ SACM APD [100]. A cross section of the layer structure is shown in Fig. 12. The first layer grown was a 100-nm-thick unintentionally doped $\mathrm{In}_{0.52} \mathrm{Al}_{0.48}$ As layer to suppress a silicon diffusion into the semi-insulating InP substrate from the $\mathrm{In}_{0.52} \mathrm{Al}_{0.48} \mathrm{As}$ n-contact layer, which can cause an excessive parasitic capacitance between contact pads. A 500-nm-thick heavily doped $\mathrm{n}^{+}$-type (silicon, $\geq 8 \times 10^{18} \mathrm{~cm}^{-3}$ ) $\operatorname{In}_{0.52} \mathrm{Al}_{0.48}$ As layer was grown as a buffer layer and was followed by a 500-nm $\mathrm{n}^{+}$-type (silicon, $\geq 5 \times 10^{18} \mathrm{~cm}^{-3}$ ) $\operatorname{In}_{0.52} \mathrm{Al}_{0.48}$ As contact layer. Following the n-type contact layer was the $I^{2} E$ multiplication region. The compound multiplication region consisted of an unintentionally doped layer of $\mathrm{In}_{0.52} \mathrm{Al}_{0.48}$ As with a thickness of $80 \mathrm{~nm}$, an unintentionally doped $\operatorname{In}_{0.53} \mathrm{Ga}_{0.17} \mathrm{Al}_{0.3} \mathrm{As}$ layer with a thickness of $80 \mathrm{~nm}$, a p-type (Be, $2.2 \times$ $10^{17} \mathrm{~cm}^{-3}$ ) 120-nm-thick $\operatorname{In}_{0.53} \mathrm{Ga}_{0.17} \mathrm{Al}_{0.3} \mathrm{As}$, and an 80-nmthick $\operatorname{In}_{0.52} \mathrm{Al}_{0.48} \mathrm{As}$ layer with the same p-type doping level.

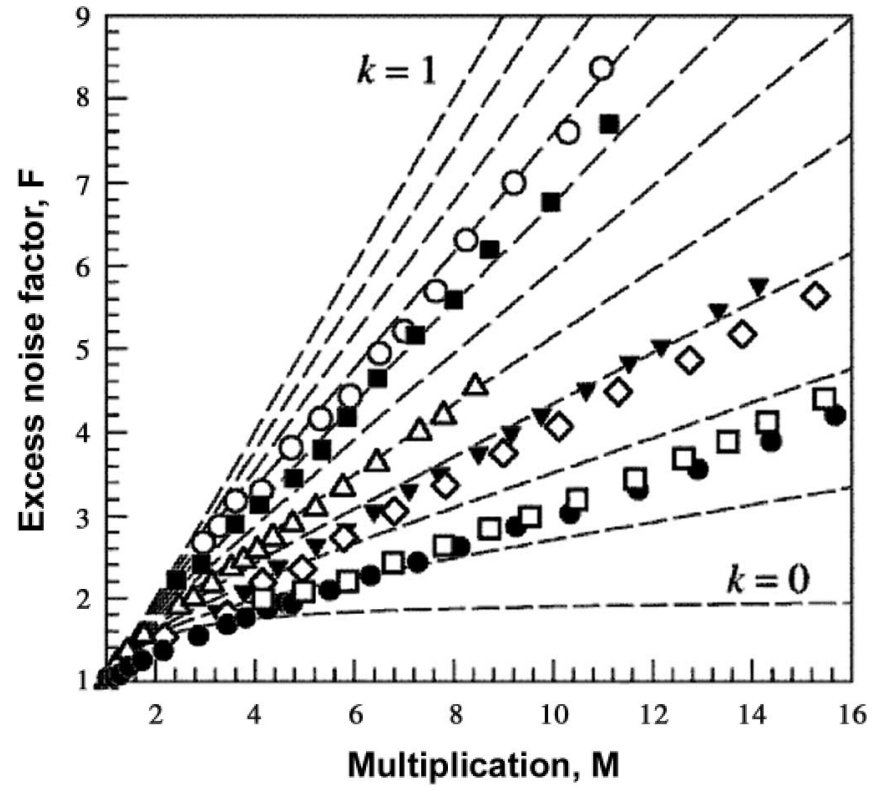

Fig. 11. Excess noise factor for "thick" $\mathrm{Al}_{x} \mathrm{Ga}_{1-x} \mathrm{As} \mathrm{p}^{+} \mathrm{in}^{+} \mathrm{APDs}$ for $x=0.4(\bigcirc), 0.5(\boldsymbol{\square}), 0.6(\triangle), 0.65(\boldsymbol{\nabla}), 0.7(\diamond), 0.8(\bullet)$, and $0.9(\square)$ [73].

The latter two layers also served as the field control or "charge" region. A 420-nm-thick intrinsic $\operatorname{In}_{0.53} \mathrm{Ga}_{0.47}$ As layer was grown as the absorbing layer. Undoped InGaAlAs grading layers $(50 \mathrm{~nm})$ were inserted to reduce the barrier between $\operatorname{In}_{0.52} \mathrm{Al}_{0.48}$ As and $\mathrm{In}_{0.53} \mathrm{Ga}_{0.47} \mathrm{As}$ in order to prevent a carrier pileup at the heterointerface. The absorber was slightly p-doped in order to suppress the impact ionization in the absorption region. Ideally, the doping in the absorber would be graded to provide a slightly higher field in the direction of the multiplication region. This was approximated by step doping the absorber in two regions, one at $1 \times 10^{16} / \mathrm{cm}^{3}$ and the other at $4 \times 10^{16} / \mathrm{cm}^{3}$. After the top grading layer, a $400-\mathrm{nm}$ thick p-type (Be-doped, $4 \times 10^{18} \mathrm{~cm}^{-3}$ ) $\mathrm{In}_{0.52} \mathrm{Al}_{0.48}$ As window layer was grown. The p-type contact layers consisted of $100 \mathrm{~nm}$ of $\operatorname{In}_{0.52} \mathrm{Al}_{0.48} \mathrm{As}\left(\mathrm{Be}: \geq 9 \times 10^{18} \mathrm{~cm}^{-3}\right)$ capped with $50 \mathrm{~nm}$ of $\mathrm{In}_{0.53} \mathrm{Ga}_{0.47}$ As doped at the same level. Based on Monte Carlo simulations of similar GaAs/ $\mathrm{Al}_{x} \mathrm{Ga}_{1-x}$ As $I^{2} E$ 


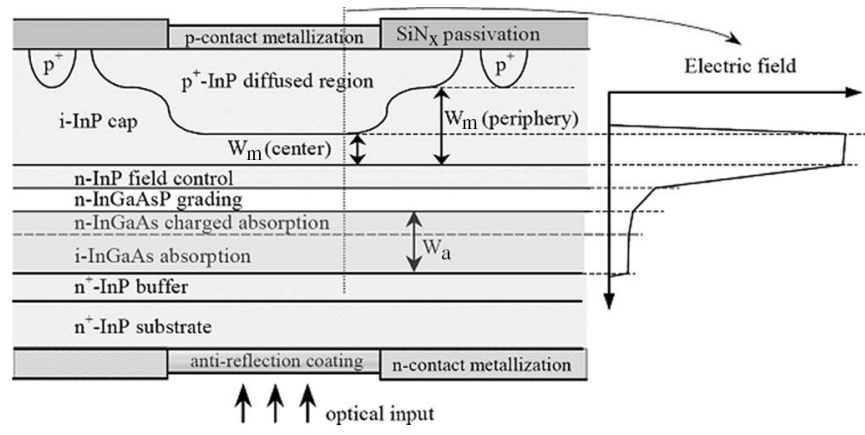

Fig. 12. Layer structure of SACM InAlAs/InGaAlAs APD with $I^{2} E$ multiplication region [100].

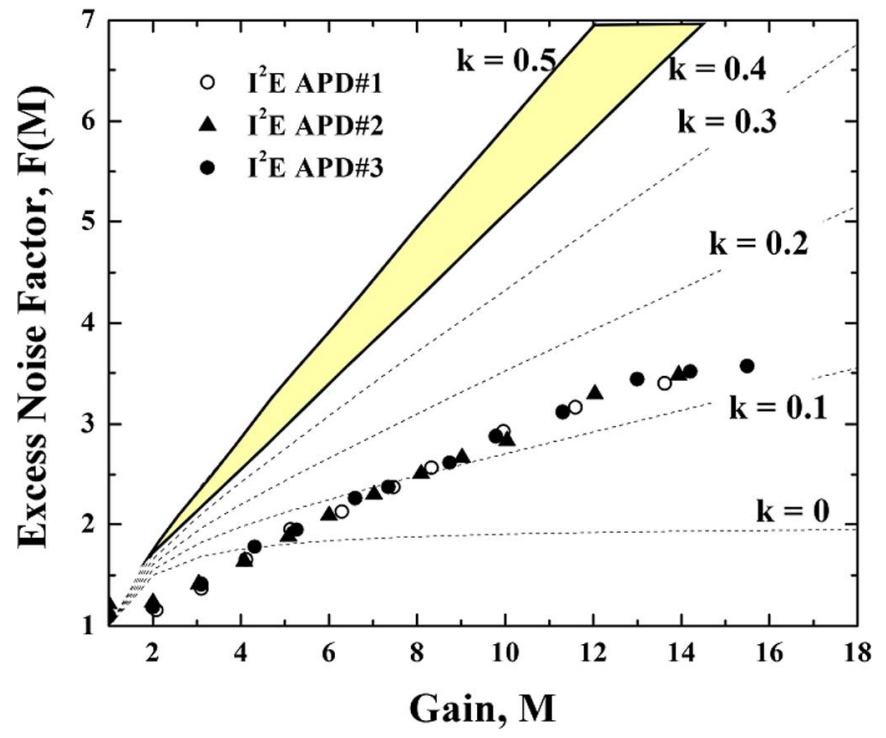

Fig. 13. Excess noise factor $F(M)$ versus gain for an SACM APD with $I^{2} E$ $\mathrm{In}_{0.52} \mathrm{Ga}_{0.15} \mathrm{Al}_{0.33} \mathrm{As} / \mathrm{In}_{0.52} \mathrm{Al}_{0.48} \mathrm{As}$ multiplication region [100].

APDs [96], it can be inferred that there are relatively few ionization events in the $\operatorname{In}_{0.52} \mathrm{Al}_{0.48}$ As layer, owing to the combined effects of "dead space" and the higher threshold energy in $\operatorname{In}_{0.52} \mathrm{Al}_{0.48}$ As. Fig. 13 shows the excess noise factor $F(M)$ versus gain. The dotted lines in Fig. 13 are plots of $F(M)$ for $k=0$ to 0.5 using the local field model. For $M \leq 4$, it appears that $k<0$, which is unphysical and simply reflects the inapplicability of the local field model for this type of multiplication region. At higher gain, the excess noise is equivalent to a $k$ value of $\sim 0.12$. For reference, the excess noise factor for $\operatorname{InP} / \mathrm{In}_{0.53} \mathrm{Ga}_{0.47}$ As SACM APDs is shown as the shaded region in Fig. 13.

An important question is whether the excess noise for these heterojunction APDs is lower than it would be in the homojunction APDs having the same multiplication width and composed of either of the constituent materials. Since most of the impact ionization occurs in the narrow bandgap region, it might also be appropriate to compare to homojunction APDs having a multiplication thickness equal to that of the narrow bandgap region in the heterojunction devices. Groves et al. [95] studied the avalanche multiplication and excess noise on a series of $\mathrm{Al}_{x} \mathrm{Ga}_{1-x} \mathrm{As}-\mathrm{GaAs}$ and $\mathrm{GaAs}-\mathrm{Al}_{x} \mathrm{Ga}_{1-x} \mathrm{As}(x=0.3,0.45$, and 0.6) single heterojunction $\mathrm{p}^{+} \mathrm{in}^{+}$diodes and concluded that the properly designed heterojunctions can reduce the noise.
They attribute this to two functions provided by the wide bandgap layer. Electrons gain energy in the wide bandgap layer but do not readily ionize, owing to its high threshold energy. The hot electrons are then injected into the GaAs region, which has lower threshold energy, where they more readily ionize. The wide bandgap layer also effectively suppresses the hole ionization. Both of these effects reduce the excess noise. Hayat et al. [103] have developed a modified dead space multiplication theory to describe the injection of carriers with a substantial kinetic energy into the multiplication region and have identified a mechanism, the "initial-energy effect," that reduces the excess noise. The energy buildup can occur through a sharp electric field gradient or, in the case of $I^{2} E$ structures, in a wide bandgap injector [94]. The initial energy of the injected carriers is linked to a reduced noise through a reduction in the initial dead space associated with the injected avalancheinitiating carrier, i.e., "the strong localization of the first impact ionization event at the beginning of the multiplication region...is akin to having two injected carriers per absorbed photon" [103].

In order to circumvent the responsivity-bandwidth tradeoff that restricts a high-speed operation of the normal-incidence PIN photodiodes, waveguide structures have been developed [104]-[108]. Input is achieved by direct coupling to the edge of the photodiode or evanescently using tapered couplers or optical matching layers. In order to achieve the bandwidths required for future high-bit-rate fiber optic systems, SACM APDs have been incorporated into edge-coupled [109]-[114] and evanescently coupled [115], [116] waveguide photodiodes. Nakata et al. [111] have reported an edge-coupled $\mathrm{In}_{0.52} \mathrm{Al}_{0.48} \mathrm{As} / \mathrm{In}_{0.53} \mathrm{Ga}_{0.47} \mathrm{As}$ APD (Fig. 14) that achieved $0.73 \mathrm{~A} / \mathrm{W}$ responsivity, low gain bandwidth of 35 , and $140-\mathrm{GHz}$ gain-bandwidth product. At $40 \mathrm{~Gb} / \mathrm{s}$, the receiver sensitivity was $-19 \mathrm{dBm}$ for $10^{-10}$ bit error rate. Fig. 15 shows the eye diagrams for $M=3,5$, and 10 and bit-error-rate plot at $40 \mathrm{~Gb} / \mathrm{s}$. At $10 \mathrm{~Gb} / \mathrm{s}$, the receiver sensitivity of $-30.2 \mathrm{dBm}$ was obtained with a similar edge-coupled APD having an asymmetric waveguide [112]. Demiguel et al. [116] have reported an evanescently coupled $\operatorname{In}_{0.52} \mathrm{Al}_{0.48} \mathrm{As} / \mathrm{In}_{0.53} \mathrm{Ga}_{0.47} \mathrm{As}$ SACM APD having a planar short multimode input waveguide. A schematic cross section of this APD is shown in Fig. 16. The planar (i.e., without lateral confinement) multimode waveguide consisted of a diluted waveguide and two optical matching layers. The diluted waveguide was a stack of ten periods of undoped 100-nm/80-nm InP/GaInAsP (1.1- $\mu \mathrm{m}$ bandgap) layers. The number of periods was optimized to achieve a high coupling efficiency with an input fiber and low TE/TM polarization dependence. The two optical matching layers were $\mathrm{n}$-doped GaInAsP with bandgaps (thickness) corresponding to $1.1 \mu \mathrm{m}(0.65 \mu \mathrm{m})$ and $1.4 \mu \mathrm{m}(0.1 \mu \mathrm{m})$ for the first and second optical matching layers, respectively. This provides a gradual increase of the optical refractive index from the diluted waveguide to the APD. The SACM APD consisted, starting from the bottom, of an n-type InAlAs layer, an undoped AlInAs multiplication region of $150 \mathrm{~nm}$, a p-type 50-nm-thick InAlAs charge layer with a nominal doping level of $8 \times 10^{17} \mathrm{~cm}^{-3}$, an undoped 30-nm-thick graded layer, an InGaAs absorbing layer, two 20-nm-thick InGaAsP "grading" layers (1.4- and $1.1-\mu \mathrm{m}$ bandgaps), and an InGaAs contact layer. The absorbing 


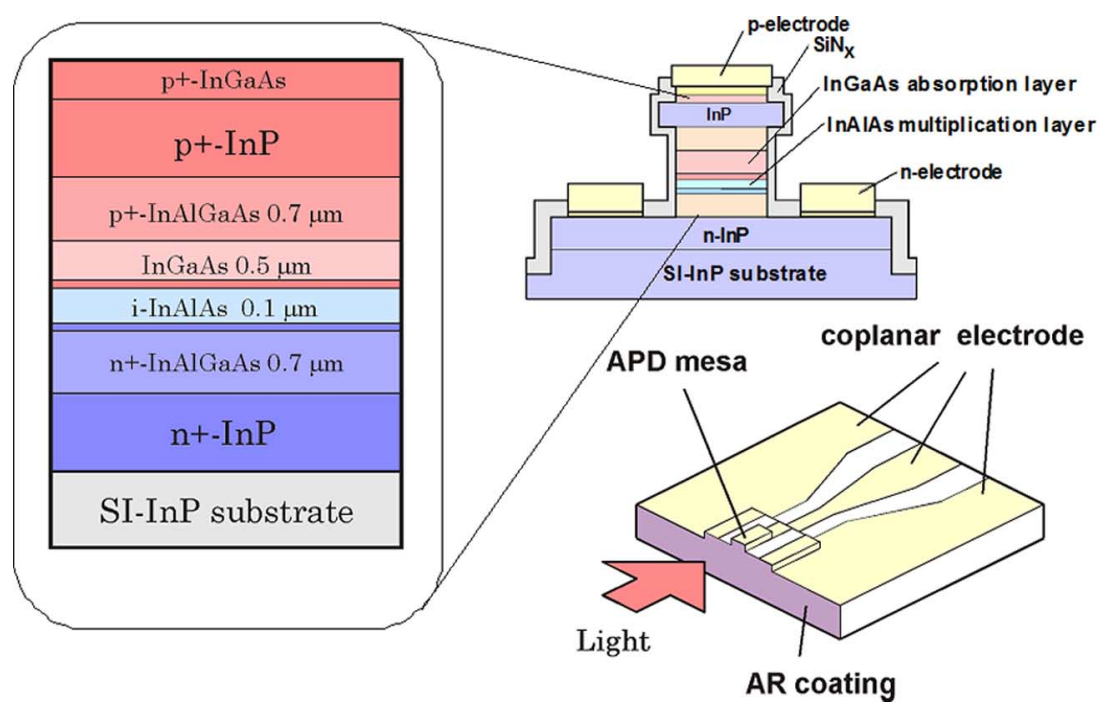

Fig. 14. Edge-coupled $\operatorname{In}_{0.52} \mathrm{Al}_{0.48} \mathrm{As} / \mathrm{In}_{0.53} \mathrm{Ga}_{0.47} \mathrm{As} \mathrm{APD}[111]$.
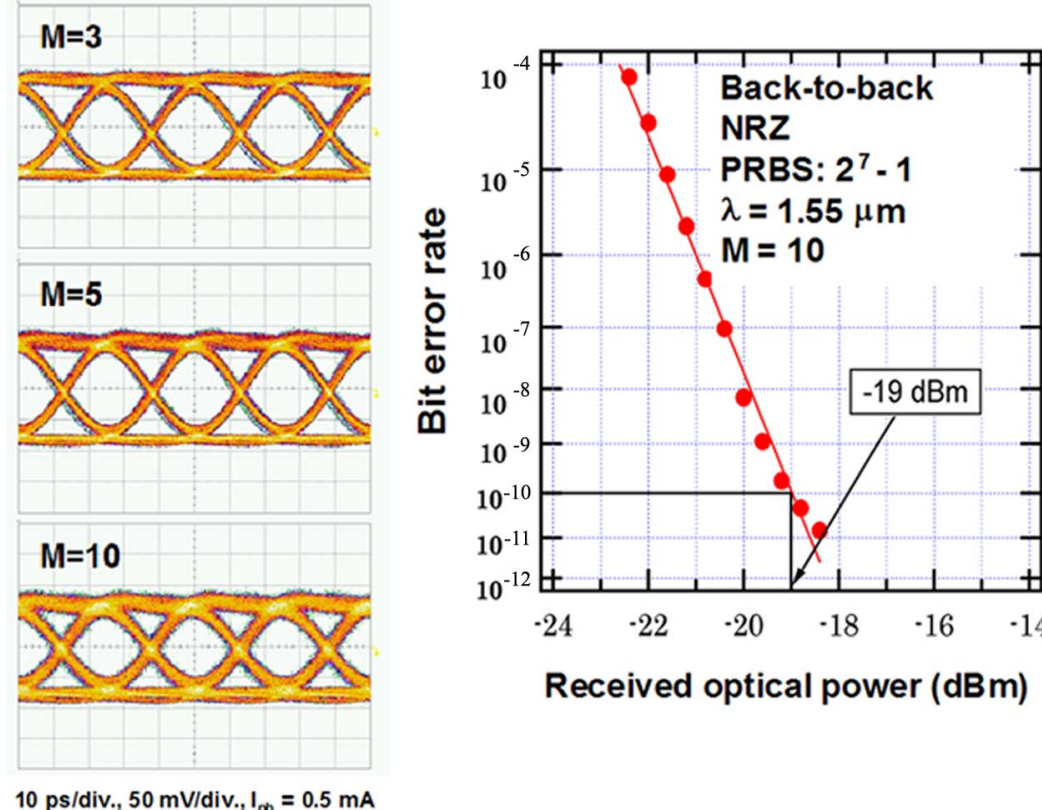

Received optical power (dBm)

$10 \mathrm{ps} /$ div., $50 \mathrm{mV} / \mathrm{div} . \mathrm{I}_{\mathrm{ph}}=0.5 \mathrm{~mA}$

Fig. 15. Eye diagrams at $M=3,5$, and 10 and bit error rate at $40 \mathrm{~Gb} / \mathrm{s}$ for edge-coupled $\operatorname{In}_{0.52} \mathrm{Al}_{0.48} \mathrm{As}_{\mathrm{I}} / \mathrm{In}_{0.53} \mathrm{Ga}_{0.47} \mathrm{As} \mathrm{APD}$ [111].

layer thickness was $190 \mathrm{~nm}$, resulting in a total active SACM as thin as $0.46-\mu \mathrm{m}$, which resulted in short transit times enabling high-speed operation. Coupling from the input waveguide into the photodiode is illustrated below the device in the graph of the field intensity along the incident axis. The photocurrent, dark current, and gain versus reverse bias are plotted in Fig. 17(a). The breakdown occurred at $\sim 18.5 \mathrm{~V}$, and the dark current at $90 \%$ of the breakdown was in the range from 100 to $500 \mathrm{nA}$. The responsivity was $0.62 \mathrm{~A} / \mathrm{W}$ with TE/TM polarization dependence of $<0.5 \mathrm{~dB}$. Fig. 17(b) shows the bandwidth versus gain; at low gain, the bandwidth was $35-\mathrm{GHz}$ maximum bandwidth, and the high-gain response exhibits a gain-bandwidth product of $160 \mathrm{GHz}$. The $-1-\mathrm{dB}$ alignment horizontal and vertical tolerances for a 5 - $\mu \mathrm{m}$ wide diode were \pm 1.8 and $\pm 0.9 \mu \mathrm{m}$, respectively.
Quantum cryptography or quantum key distribution is a rapidly emerging field of optical fiber communications [117]. The goal is to provide a shared secret key to two authorized parties who desire to communicate securely, even if an eavesdropper has an access to all of the message traffic. A key feature of the quantum cryptography is that it provides the ultimate security based on the quantum mechanical properties of single photons. These systems are presently being studied and developed in laboratories around the world. A critical function for these systems is a single photon detection with high efficiency and minimal false positives. The photodetector of choice is the single photon counting avalanche photodetector (SPAD). The operation of an APD below a breakdown voltage is referred to as a linear mode operation. Operation above the breakdown voltage is fundamentally different. Above breakdown, an APD 


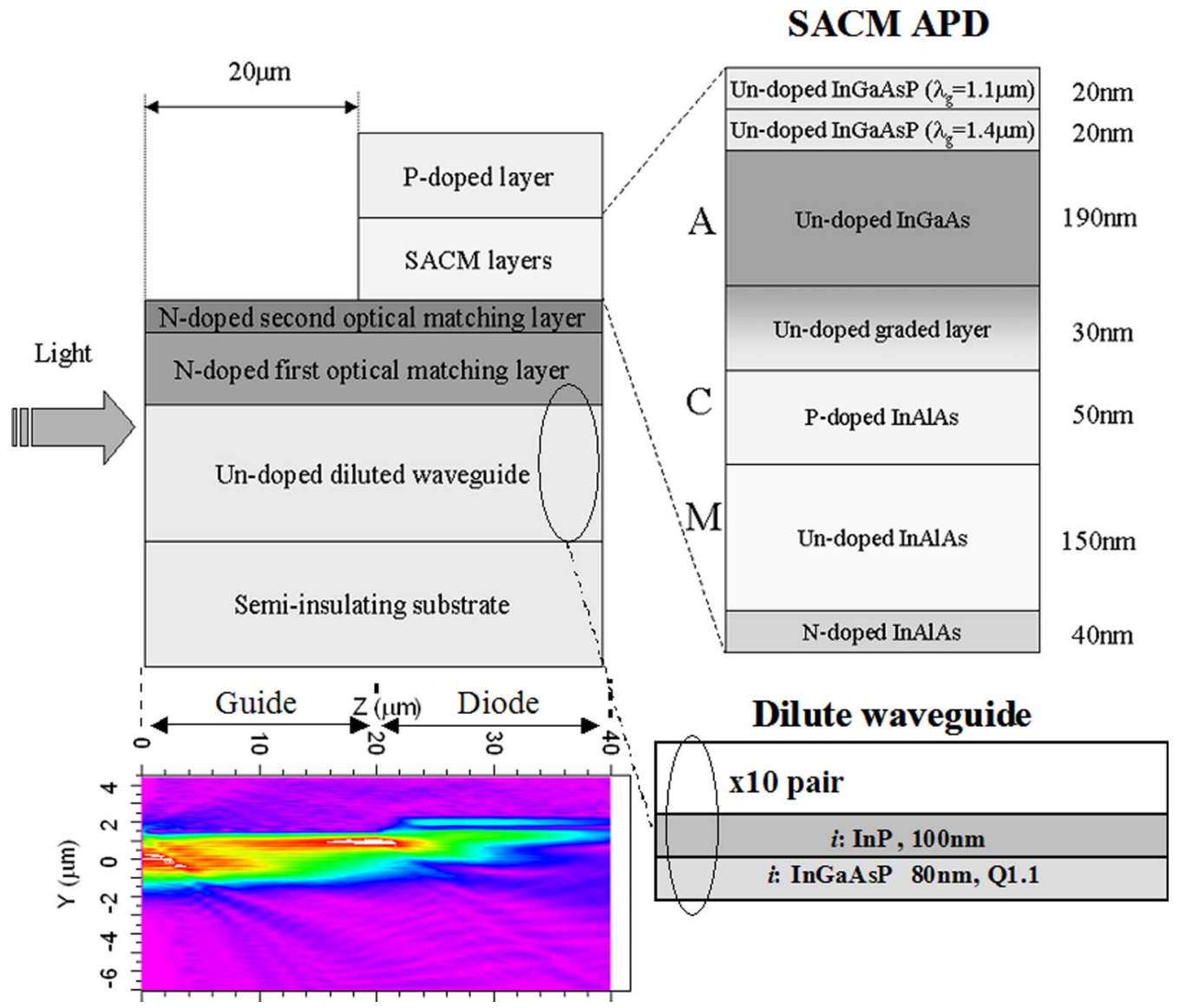

Fig. 16. Schematic cross section of evanescently coupled InAlAs/InAlAs waveguide APD [116].

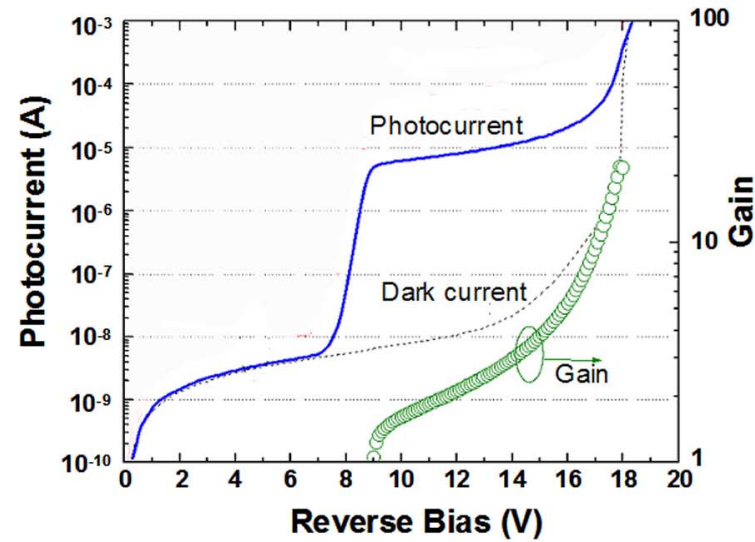

(a)

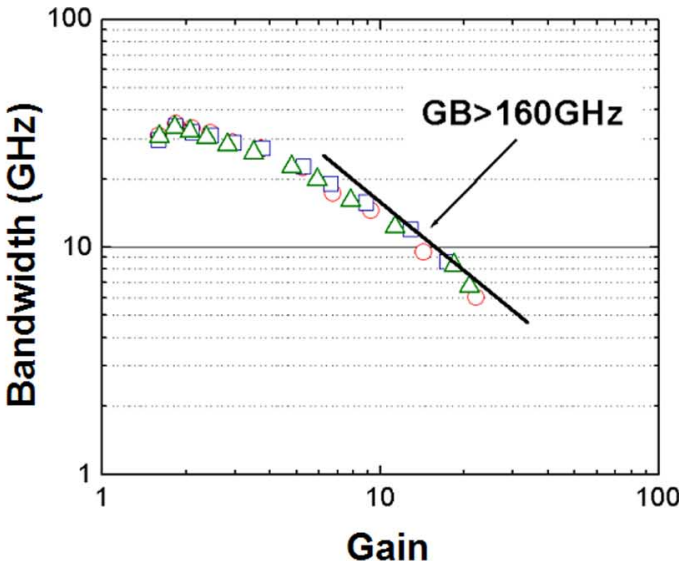

(b)

Fig. 17. (a) Photocurrent, dark current, and gain and (b) bandwidth versus gain of evanescently coupled InAlAs/InAlAs waveguide APD [116].

acts as a trigger element similar to a Geiger-Muller counter of nuclear radiation. Consequently, this mode of operation is frequently referred to as the Geiger-mode operation. In the Geiger mode, an APD sustains the high bias across the depletion layer until a carrier is injected into the multiplication region. Once a carrier has initiated an avalanche process, owing to the high field, the current will continue to increase limited only by the external circuit. The net result is that a macroscopic current pulse is produced in response to a single carrier in the depletion layer. This is the "ON" state of the Geiger-mode APD.
The single carrier can be photogenerated, by which the single photon detection is achieved, or may have its origin in the dark current, giving rise to a dark count. Optimum performance is achieved when the single photon detection efficiency is high, and the dark count rate is low.

The first SPADs were $\mathrm{Si}$, and these devices still achieve the best performance; a good review of the history of Si SPADs and state-of-the-art performance can be found in [118]. The development of fiber optic distribution systems has created a need for long-wavelength SPADs. To that end, InP/InGaAs 


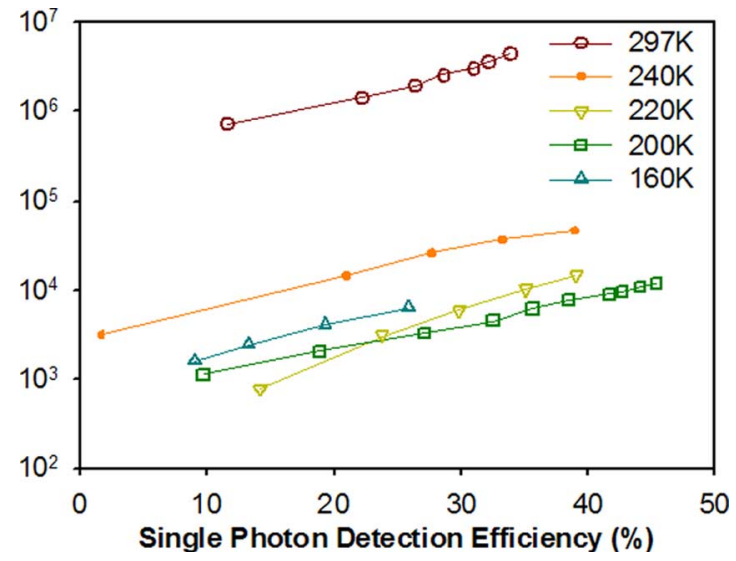

Fig. 18. Dark count rate versus single photon detection efficiency for InP/InGaAs SPAD [122].

SACM SPADs have been studied widely as single-photon counters. Although most of these studies have used commercially available APDs that were designed for fiber optic transmission, recently, there have been some efforts in designing InP-based SACM APDs for single photon counting applications [119]-[121]. Liu et al. [122] have reported the high single photon detection efficiency $(\sim 45 \%)$ and low dark count rate $\left(<10^{4} / \mathrm{s}\right)$ with an InP/InGaAs SACM APD similar in structure to that in Fig. 1. Fig. 18 shows the dark count rate versus the single photon detection efficiency at $1.31 \mu \mathrm{m}$. Essentially, identical results were achieved at $1.55 \mu \mathrm{m}$. The reason that the dark count rate increases with the increasing detection efficiency is that higher detection efficiencies are achieved by increasing the excess bias above breakdown, which results in higher dark counts. While room temperature operation has been achieved, it is clear that cooling reduces the dark count rate by over two orders of magnitude. The single photon detection efficiency is the product of the external quantum efficiency and the probability that a photogenerated carrier will initiate an avalanche breakdown. As a result, the external quantum efficiency (68\% for these APDs) is the theoretical maximum for single photon detection efficiency; hence, for these APDs, $\sim 60 \%$ of the photons that are absorbed are counted.

In the past decade, the performance of APDs for optical fiber communication systems has improved as a result of improvements in materials and the development of advanced device structures. Techniques to reduce the excess noise and increase the gain-bandwidth product have enabled the operation at higher bit rates and set the stage for future systems that will benefit from the compact size, low cost, and high sensitivity that the APDs provide.

\section{REFERENCES}

[1] S. D. Personick, "Receiver design for digital fiber-optic communication systems, Parts I and II,” Bell Syst. Tech. J., vol. 52, no. 6, pp. 843-886, Jul./Aug. 1973.

[2] R. G. Smith and S. D. Personick, "Receiver design for optical fiber communications systems," in Semiconductor Devices for Optical Communication. New York: Springer-Verlag, 1980, ch. 4.

[3] S. R. Forrest, "Sensitivity of avalanche photodetector receivers for highbit-rate long-wavelength optical communication systems," in Semiconductors and Semimetals, vol. 22. Orlando, FL: Academic, 1985, ch. 4.
[4] B. L. Kasper and J. C. Campbell, "Multigigabit-per-second avalanche photodiode lightwave receivers," J. Lightw. Technol., vol. LT-5, no. 10, pp. 1351-1364, Oct. 1987.

[5] H. Melchior, A. R. Hartman, D. P. Schinke, and T. E. Seidel, "Planar epitaxial silicon avalanche photodiode," Bell Syst. Tech. J., vol. 57, no. 6, pp. 1791-1807, 1978.

[6] S. R. Forrest, M. DiDomenico, Jr., R. G. Smith, and H. J. Stocker, "Evidence of tunneling in reverse-bias III-V photodetector diodes," Appl. Phys. Lett., vol. 36, no. 7, pp. 580-582, Apr. 1980.

[7] H. Ando, H. Kaaba, M. Ito, and T. Kaneda, "Tunneling current in InGaAs and optimum design for InGaAs/InP avalanche photo-diodes," Jpn. J. Appl. Phys., vol. 19, no. 6, pp. L277-L280, Jun. 1980.

[8] K. Nishida, K. Taguchi, and Y. Matsumoto, "InGaAsP heterojunction avalanche photodiodes with high avalanche gain," Appl. Phys. Lett., vol. 35, no. 3, pp. 251-253, Aug. 1979.

[9] S. R. Forrest, O. K. Kim, and R. G. Smith, "Optical response time of $\mathrm{In}_{0.53} \mathrm{Ga}_{0.47}$ As avalanche photodiodes," Appl. Phys. Lett., vol. 41, no. 1, pp. 95-98, Jul. 1982.

[10] F. Capasso, H. M. Cox, A. I. Hutchinson, N. A. Olson, and S. G. Hummel, "Pseudo-quaternary GaInAsP semiconductors: A new $\mathrm{Ga}_{0.47} \mathrm{In}_{0.53} \mathrm{As} / \mathrm{InP}$ graded gap superlattice and its applications to avalanche photodiodes," Appl. Phys. Lett., vol. 45, no. 11, pp. $1193-$ 1195, Dec. 1984.

[11] H. Kuwatsuka, Y. Kito, T. Uchida, and T. Mikawa, "High-speed InP/ InGaAs avalanche photodiodes with a compositionally graded quaternary layer,' IEEE Photon. Technol. Lett., vol. 3, no. 12, pp. 1113-1114, Dec. 1991.

[12] J. C. Campbell, A. G. Dentai, W. S. Holden, and B. L. Kasper, "Highperformance avalanche photodiode with separate absorption, grading, and multiplication regions," Electron. Lett., vol. 18, no. 20, pp. 818-820, 1983.

[13] Y. Matsushima, A. Akiba, K. Sakai, K. Kushirn, Y. Node, and K. Utaka, "High-speed response InGaAs/InP heterostructure avalanche photodiode with InGaAsP buffer layers," Electron. Lett., vol. 18, no. 22, pp. 945946, Oct. 1982.

[14] F. Capasso, A. Y. Cho, and P. W. Foy, "Low-dark-current low-voltage 1.3-1.6 $\mu \mathrm{m}$ avalanche photodiode with high-low electric field profile and separate absorption and multiplication regions by molecular beam epitaxy," Electron. Lett., vol. 20, no. 15, pp. 635-637, Jul. 1984.

[15] P. Webb, R. McIntyre, J. Scheibling, and M. Holunga, "A planar InGaAs APD fabricated using Si implantation and regrowth techniques," in Tech. Dig. Opt. Fiber Conf., New Orleans, LA, 1988, p. 129.

[16] L. E. Tarof, "Planar InP-InGaAs avalanche photodetectors with n- multiplication layer exhibiting a very high gain-bandwidth product," IEEE Photon. Technol. Lett., vol. 2, no. 9, pp. 643-646, Sep. 1990.

[17] H. W. Ruegg, "An optimized avalanche photodiode," IEEE Trans. Electron Devices, vol. ED-14, no. 5, pp. 239-251, 1967.

[18] K. Taguchi, T. Torikai, Y. Sugimoto, K. Makita, and H. Ishihara, "Planarstructure InP/InGaAsP/InGaAs avalanche photodiodes with preferential lateral extended guard ring for 1.0-1.6 $\mu \mathrm{m}$ wavelength optical communication use," J. Lightw. Technol., vol. 6, no. 11, pp. 1643-1655, Nov. 1988.

[19] Y. Matsushima, Y. Noda, Y. Kushiro, N. Seki, and S. Akiba, "High sensitivity of VPE-grown InGaAs/InP-heterostructure APD with buffer layer and guard-ring structure," Electron. Lett., vol. 20, no. 6, pp. 235-236, Mar. 1984.

[20] J. N. Hollenhorst, D. T. Ekholm, J. M. Geary, V. D. Mattera, Jr., and R. Pawalek, "High frequency performance of planar InGaAs/InP APDs," in Proc. SPIE, High Freq. Analog Commun., 1988, vol. 995, pp. 53-60.

[21] Y. Liu, S. R. Forrest, J. Hladky, M. J. Lange, G. H. Olsen, and D. E. Ackly, "A planar InP/InGaAs avalanche photodiode with floating guard ring and double diffused junction," J. Lightw. Technol., vol. 10, no. 2, pp. 182-193, Feb. 1992.

[22] M. A. Itzler, K. K. Loi, S. McCoy, N. Codd, and N. Komaba, "Manufacturable planar bulk-InP avalanche photodiodes for $10 \mathrm{~Gb} / \mathrm{s}$ applications," in Proc. LEOS, San Francisco, CA, Nov. 1999, pp. 748-749.

[23] S. R. Cho, S. K. Yang, J. S. Ma, S. D. Lee, J. S. Yu, A. G. Choo, T. I. Kim, and J. Burm, "Suppression of avalanche multiplication at the periphery of diffused junction by floating guard rings in a planar In-GaAs-InP avalanche photodiode," IEEE Photon. Technol. Lett., vol. 12, no. 5, pp. 534-536, May 2000.

[24] J. Wei, J. C. Dries, H. Wang, M. L. Lange, G. H. Olsen, and S. R. Forrest, "Optimization of 10-Gb/s long-wavelength floating guard ring InGaAsInP avalanche photodiodes," IEEE Photon. Technol. Lett., vol. 14, no. 7, pp. 977-979, Jul. 2002.

[25] L. E. Tarof, D. G. Knight, K. E. Fox, C. J. Miner, N. Puetz, and H. B. Kim, "Planar InPAnGaAs avalanche photodiodes with partial 
charge sheet in device periphery," Appl. Phys. Lett., vol. 57, no. 7, pp. 670-672, Aug. 1990.

[26] L. E. Tarof, R. Bruce, D. G. Knight, J. Yu, H. B. Kim, and T. Baird, "Planar InP-InGaAs single growth avalanche photodiodes with no guard rings," IEEE Photon. Technol. Lett., vol. 7, no. 11, pp. 1330-1332, Nov. 1995

[27] C. Y. Park, K. S. Hyun, S. K. Kang, M. K. Song, T. Y. Yoon, H. M. Kim, H. M. Park, S.-C. Park, Y. H. Lee, C. Lee, and J. B. Yoo, "Highperformance InGaAs/InP photodiode for $2.5 \mathrm{~Gb} / \mathrm{s}$ optical receiver," Opt. Quantum Electron., vol. 24, no. 5, pp. 553-559, 1995.

[28] G. Hasnain, W. G. Bi, S. Song, J. T. Anderson, N. Moll, C.-Y. Su, J. N. Hollenhorst, N. D. Baynes, I. Athroll, S. Amos, and R. M. Ash, "Buried-mesa avalanche photodiodes," IEEE J. Quantum Electron., vol. 34, no. 12, pp. 2321-2326, Dec. 1998.

[29] M. A. Itzler, C. S. Wang, S. McCoy, N. Codd, and N. Komaba, "Planar bulk InP avalanche photodiode design for 2.5 and $10 \mathrm{~Gb} / \mathrm{s}$ applications," in Proc. 24th ECOC, Madrid, Spain, Sep. 20-24, 1998, vol. 1, pp. 59-60.

[30] D. A. Humphreys and R. J. King, "Measurement of absorption coefficients of $\mathrm{Ga}_{0.47} \mathrm{In}_{0.53}$ As over the wavelength range $1.0-1.7 \mu \mathrm{m}$," Electron. Lett., vol. 21, no. 25/26, pp. 1187-1189, Dec. 1985.

[31] F. R. Bacher, J. S. Blakemore, J. T. Ebner, and J. R. Arthur, "Opticalabsorption coefficient of $\mathrm{In}_{1-\mathrm{x}} \mathrm{Ga}_{\mathrm{x}} \mathrm{As} / \mathrm{InP}$," Phys. Rev. B, Condens. Matter, vol. 37, no. 5, pp. 2551-2557, Feb. 1988.

[32] C. A. Amiento and S. H. Groves, "Impact ionization in (100)-, (110)-, and (111)- oriented InP avalanche photodiodes," Appl. Phys. Lett., vol. 43, no. 2, pp. 333-335, 1983.

[33] L. W. Cook, G. E. Bulman, and G. E. Stillman, "Electron and hole ionization coefficients in InP determined by photomultiplication measurements," Appl. Phys. Lett., vol. 40, no. 7, pp. 589-591, Apr. 1982.

[34] R. J. McIntyre, "Multiplication noise in uniform avalanche diodes," IEEE Trans. Electron Devices, vol. ED-13, no. 1, pp. 164-168, Jan. 1966.

[35] _ - "The distribution of gains in uniformly multiplying avalanche photodiodes: Theory," IEEE Trans. Electron Devices, vol. ED-19, no. 6, pp. 703-713, Jun. 1972.

[36] _ - "Factors affecting the ultimate capabilities of high speed avalanche photodiodes and a review of the state-of-the-art," in Tech. Dig. Int. Electron Devices Meeting, 1973, pp. 213-216.

[37] Y. Okuto and C. R. Crowell, "Ionization coefficients in semiconductors: A nonlocalized property," Phys. Rev. B, Condens. Matter, vol. 10, no. 10, pp. 4284-4296, Nov. 1974.

[38] R. B. Emmons, "Avalanche-photodiode frequency response," J. Appl. Phys., vol. 38, no. 9, pp. 3705-3714, Aug. 1967.

[39] C. A. Lee, R. A. Logan, R. L. Batdorf, J. J. Kleimack, and W. Weigmann, "Ionization rates of holes and electrons in silicon," Phys. Rev., vol. 134, no. 3A, pp. A761-A773, 1964.

[40] J. Conradi, "The distributions of gains in uniformly multiplying avalanche photodiodes: Experimental," IEEE Trans. Electron Devices, vol. ED-19, no. 6, pp. 713-718, Jun. 1972.

[41] W. N. Grant, "Electron and hole ionization rates in epitaxial silicon at high electric fields," Solid State Electron., vol. 16, no. 10, pp. 11891203, Oct. 1973

[42] T. Kaneda, H. Matsumoto, and T. Yamaoka, "A model for reachthrough avalanche photodiodes (RAPD's)," J. Appl. Phys., vol. 47, no. 7, pp. 3135-3139, Jul. 1976.

[43] J. D. Beck, C. F. Wan, M. A. Kinch, and J. E. Robinson, "MWIR HgCdTe avalanche photodiodes," in Proc. SPIE Mater. Infrared Detectors, 2001, vol. 4454, pp. 188-197.

[44] J. D. Beck, C.-F. Wan, M. A. Kinch, J. E. Robinson, F. Ma, and J. C. Campbell, "The HgCdTe electron avalanche photodiode," in Proc. IEEE LEOS Annu. Meeting, 2003, vol. 2, pp. 849-850. (IEEE Cat. 03CH37460).

[45] F. Ma, X. Li, J. C. Campbell, J. D. Beck, C.-F. Wan, and M. A. Kinch, "Monte Carlo simulations of $\mathrm{Hg}_{0.7} \mathrm{Cd}_{0.3} \mathrm{Te}$ avalanche photodiodes and resonance phenomenon in the multiplication noise," Appl. Phys. Lett., vol. 83 , no. 4, pp. 785-787, Jul. 2003.

[46] A. R. Hawkins, T. E. Reynolds, D. R. England, D. I. Babic, M. J. Mondry, K. Streubel, and J. E. Bowers, "Silicon heterointerface photodetector," Appl. Phys. Lett., vol. 68, no. 26, pp. 3692-3694, Jun. 24, 1996.

[47] Y. Kang, P. Mages, A. R. Clawson, P. K. L. Yu, M. Bitter, Z. Pan, A. Pauchard, S. Hummel, and Y. H. Lo, "Fused InGaAs-Si avalanche photodiodes with low-noise performances," IEEE Photon. Technol. Lett., vol. 14, no. 11, pp. 1593-1595, Nov. 2002.

[48] M. Bitter, Z. Pan, S. Kristjansson, L. Boman, R. Gold, and A. Pauchard, "InGaAs-on-Si photodetectors for high-sensitivity detection," in Proc. SPIE Infrared Technol. and Appl. XXX, 2004, vol. 5406, pp. 1-12.
[49] H.-W. Lee and A. R. Hawkins, "Solid-state current amplifier based on impact ionization," Appl. Phys. Lett., vol. 87, no. 7, pp. 73511-173511-3, Aug. 2005.

[50] H.-W. Lee, J. L. Beutler, and A. R. Hawkins, "Solid-state current amplifier based on impact ionization," Opt. Express, vol. 13, no. 10, pp. 8760-8765, 2005 .

[51] _ , "High gain effects for solid-state impact-ionization multipliers," IEEE J. Quantum Electron., vol. 42, no. 5, pp. 471-476, May 2006.

[52] M. M. Hayat, B. E. A. Saleh, and M. C. Teich, "Effect of dead space on gain and noise of double-carrier multiplication avalanche photodiodes," IEEE Trans. Electron Devices, vol. 39, no. 3, pp. 546-552, Mar. 1992.

[53] R. J. McIntyre, "A new look at impact ionization-Part 1: A theory of gain, noise, breakdown probability and frequency response," IEEE Trans. Electron Devices, vol. 48, no. 8, pp. 1623-1631, 1999.

[54] X. Li, X. Zheng, S. Wang, F. Ma, and J. C. Campbell, "Calculation of gain and noise with dead space for GaAs and $\mathrm{Al}_{\mathrm{x}} \mathrm{Ga}_{1-\mathrm{x}}$ As avalanche photodiodes," IEEE Trans. Electron Devices, vol. 49, no. 7, pp. 11121117, Jul. 2002.

[55] B. Jacob, P. N. Robson, J. P. R. David, and G. J. Rees, "Fokker-Planck model for nonlocal impact ionization in semiconductors," J. Appl. Phys., vol. 90, no. 3, pp. 1314-1317, Aug. 2001

[56] A. Spinelli and A. L. Lacaita, "Mean gain of avalanche photodiodes in a dead space model," IEEE Trans. Electron Devices, vol. 43, no. 1, pp. 23-30, Jan. 1996.

[57] G. M. Dunn, G. J. Rees, J. P. R. David, S. A. Plimmer, and D. C. Herbert, "Monte Carlo simulation of impact ionization and current multiplication in short GaAs p ${ }^{+}$in ${ }^{+}$diodes," Semicond. Sci. Technol., vol. 12, no. 1, pp. 111-120, Jan. 1997.

[58] D. S. Ong, K. F. Li, G. J. Rees, G. M. Dunn, J. P. R. David, and P. N. Robson, "A Monte Carlo investigation of multiplication noise in thin $\mathrm{p}^{+}$in $^{+}$avalanche photodiodes," IEEE Trans. Electron Devices, vol. 45, no. 8, pp. 1804-1810, Aug. 1998.

[59] S. A. Plimmer, J. P. R. David, D. S. Ong, and K. F. Li, "A simple model including the effects of dead space," IEEE Trans. Electron Devices, vol. 46, no. 4, pp. 769-775, Apr. 1999.

[60] J. C. Campbell, S. Demiguel, F. Ma, A. Beck, X. Guo, S. Wang, X. Zheng, X. Li, J. D. Beck, M. A. Kinch, A. Huntington, L. A. Coldren, J. Decobert, and N. Tscherptner, "Recent advances in avalanche photodiodes," J. Sel. Topics Quantum Electron., vol. 10, no. 4, pp. 777-787, Apr. 2005.

[61] K. F. Li, S. A. Plimmer, J. P. R. David, R. C. Tozer, G. J. Rees, P. N. Robson, C. C. Button, and J. C. Clark, "Low avalanche noise characteristics in thin InP $\mathrm{p}^{+}-\mathrm{i}-\mathrm{n}^{+}$diodes with electron initiated multiplication," IEEE Photon. Technol. Lett., vol. 11, no. 3, pp. 364-366, Mar. 1999.

[62] J. C. Campbell, S. Chandrasekhar, W. T. Tsang, G. J. Qua, and B. C. Johnson, "Multiplication noise of wide-bandwidth InP/InGaAsP/ InGaAs avalanche photodiodes," J. Lightw. Technol., vol. 7, no. 3, pp. 473-478, Mar. 1989.

[63] P. Yuan, C. C. Hansing, K. A. Anselm, C. V. Lenox, H. Nie, A. L. Holmes, Jr., B. G. Streetman, and J. C. Campbell, "Impact ionization characteristics of III-V semiconductors for a wide range of multiplication region thicknesses," IEEE J. Quantum Electron., vol. 36, no. 2, pp. 198-204, Feb. 2000

[64] M. A. Saleh, M. M. Hayat, P. O. Sotirelis, A. L. Holmes, J. C. Campbell, B. Saleh, and M. Teich, "Impact-ionization and noise characteristics of thin III-V avalanche photodiodes," IEEE Trans. Electron Devices, vol. 48, no. 12, pp. 2722-2731, Dec. 2001.

[65] K. F. Li, D. S. Ong, J. P. R. David, R. C. Tozer, G. J. Rees, S. A. Plimmer, K. Y. Chang, and J. S. Roberts, "Avalanche noise characteristics of thin GaAs structures with distributed carrier generation," IEEE Trans. Electron Devices, vol. 47, no. 5, pp. 910-914, May 2000.

[66] K. F. Li, D. S. Ong, J. P. R. David, G. J. Rees, R. C. Tozer, P. N. Robson, and R. Grey, "Avalanche multiplication noise characteristics in thin GaAs $\mathrm{p}^{+}{ }_{-\mathrm{i}-\mathrm{n}^{+}}$diodes," IEEE Trans. Electron Devices, vol. 45, no. 10, pp. 2102-2107, Oct. 1998.

[67] C. Hu, K. A. Anselm, B. G. Streetman, and J. C. Campbell, "Noise characteristics of thin multiplication region GaAs avalanche photodiodes," Appl. Phys. Lett., vol. 69, no. 24, pp. 3734-3736, Dec. 1996.

[68] S. A. Plimmer, J. P. R. David, D. C. Herbert, T.-W. Lee, G. J. Rees, P. A. Houston, R. Grey, P. N. Robson, A. W. Higgs, and D. R. Wight, "Investigation of impact ionization in thin GaAs diodes," IEEE Trans. Electron Devices, vol. 43, no. 7, pp. 1066-1072, Jul. 1996.

[69] C. Lenox, P. Yuan, H. Nie, O. Baklenov, C. Hansing, J. C. Campbell, and B. G. Streetman, "Thin multiplication region InAlAs homojunction avalanche photodiodes," Appl. Phys. Lett., vol. 73, no. 6, pp. 783-784, Aug. 1998. 
[70] C. H. Tan, J. C. Clark, J. P. R. David, G. J. Rees, S. A. Plimmer, R. C. Tozer, D. C. Herbert, D. J. Robbins, W. Y. Leong, and J. Newey, "Avalanche noise measurements in thin $\mathrm{Si}^{+}{ }_{-\mathrm{i}-\mathrm{n}}{ }^{+}$diodes," Appl. Phys. Lett., vol. 76, no. 26, pp. 3926-3928, Jun. 2000.

[71] C. H. Tan, J. P. R. David, J. Clark, G. J. Rees, S. A. Plimmer, D. J. Robbins, D. C. Herbert, R. T. Carline, and W. Y. Leong, "Avalanche multiplication and noise in submicron Si p-i-n diodes," in Proc. SPIE, Silicon-Based Optoelectronics II, 2000, vol. 3953, pp. 95-102.

[72] S. A. Plimmer, J. P. R. David, G. J. Rees, R. Grey, D. C. Herbert, D. R. Wright, and A. W. Higgs, "Impact ionization in thin $\mathrm{Al}_{\mathrm{x}} \mathrm{Ga}_{1-\mathrm{x}} \mathrm{As}$ $(\mathrm{x}=0.15-0.30)$ p-i-n diodes," J. Appl. Phys., vol. 82, no. 3, pp. 1231-1235, Aug. 1997.

[73] B. K. Ng, J. P. R. David, G. J. Rees, R. C. Tozer, M. Hopkinson, and R. J. Riley, "Avalanche multiplication and breakdown in $\mathrm{Al}_{\mathrm{x}} \mathrm{Ga}_{1-\mathrm{x}} \mathrm{As}(\mathrm{x}<0.9)$," IEEE Trans. Electron Devices, vol. 49, no. 12, pp. 2349-2351, Dec. 2002.

[74] B. K. Ng, J. P. R. David, R. C. Tozer, M. Hopkinson, G. Hill, and G. H. Rees, "Excess noise characteristics of $\mathrm{Al}_{0.8} \mathrm{Ga}_{0.2} \mathrm{As}$ avalanche photodiodes," IEEE Trans. Electron Devices, vol. 48, no. 10, pp. 21982204, Oct. 2001.

[75] C. H. Tan, J. P. R. David, S. A. Plimmer, G. J. Rees, R. C. Tozer, and $\mathrm{R}$. Grey, "Low multiplication noise thin $\mathrm{Al}_{0.6} \mathrm{Ga}_{0.4}$ As avalanche photodiodes," IEEE Trans. Electron Devices, vol. 48, no. 7, pp. 13101317, Jul. 2001.

[76] B. K. Ng, J. P. R. David, R. C. Tozer, G. J. Rees, Y. Feng, J. H. Zhao, and M. Weiner, "Nonlocal effects in thin $4 \mathrm{H}-\mathrm{SiC} \mathrm{UV}$ avalanche photodiodes," IEEE Trans. Electron Devices, vol. 50, no. 8, pp. 1724-1732, Aug. 2003.

[77] A. L. Beck, B. Yang, S. Wang, C. J. Collins, J. C. Campbell, A. Yulius, A. Chen, and J. M. Woodall, "Quasi-direct UV/blue GaP avalanche photodiodes," IEEE J. Quantum Electron., vol. 40, no. 12, pp. 16951699, Dec. 2004.

[78] C. H. Tan, R. Ghin, J. P. R. David, G. J. Rees, and M. Hopkinson, "The effect of dead space on gain and excess noise in $\operatorname{In}_{0.48} \mathrm{Ga}_{0.52} \mathrm{P} \mathrm{p}^{+}$in $^{+}$ diodes," Semicond. Sci. Technol., vol. 18, no. 8, pp. 803-806, Aug. 2003.

[79] I. Watanabe, T. Torikai, K. Makita, K. Fukushima, and T. Uji, "Impact ionization rates in (100) $\mathrm{Al}_{0.48} \mathrm{In}_{0.52} \mathrm{As}$," IEEE Electron Device Lett., vol. 11, no. 10, pp. 437-438, Oct. 1990.

[80] C. Lenox, H. Nie, P. Yuan, G. Kinsey, A. L. Holmes, Jr., B. G. Streetman, and J. C. Campbell, "Resonant-cavity InGaAs/InAlAs avalanche photodiodes with gain-bandwidth product of $290 \mathrm{GHz}$," IEEE Photon. Technol. Lett., vol. 11, no. 9, pp. 1162-1164, Sep. 1999.

[81] N. Li, R. Sidhu, X. Li, F. Ma, X. Zheng, S. Wang, G. Karve, S. Demiguel, A. L. Holmes, Jr., and J. C. Campbell, "InGaAs/InAlAs avalanche photodiode with undepleted absorber," Appl. Phys. Lett., vol. 82, no. 13, pp. 2175-2177, Mar. 2003

[82] J. C. Boisvert, A. Masalykin, G. S. Kinsey, T. Isshiki, M. Haddad, R. Sudharsanan, X. Zheng, and J. C. Campbell, "Characterization of InAlAs/InGaAs APD arrays for SWIR imaging applications," Proc. SPIE, vol. 5406, no. 1, pp. 13-20, Aug. 2004.

[83] I. Watanabe, M. Tsuji, K. Makita, and K. Taguchi, "A new planarstructure InAlGaAs-InAlAs superlattice avalanche photodiode with a Ti-implanted guard-ring," IEEE Photon. Technol. Lett., vol. 8, no. 6, pp. 827-829, Jun. 1996.

[84] I. Watanabe, T. Nakata, M. Tsuji, K. Makita, and K. Taguchi, "Highreliability and low-dark-current $10-\mathrm{Gb} / \mathrm{s}$ planar superlattice avalanche photodiodes," IEEE Photon. Technol. Lett., vol. 9, no. 12, pp. 16191621, Dec. 1997.

[85] E. Yagyu, E. Ishimura, M. Nakaji, T. Aoyagi, and Y. Tokuda, "Simple planar structure for high-performance AlInAs avalanche photodiodes," IEEE Photon. Technol. Lett., vol. 18, no. 1, pp. 76-78, Jan. 2006.

[86] E. Yagyu, E. Ishimura, M. Nakaji, T. Aoyagi, K. Yoshiara, and Y. Tokuda, "Investigation of guardring-free planar AlInAs avalanche photodiodes," IEEE Photon. Technol. Lett., vol. 18, no. 11, pp. 12641266, Jun. 2006.

[87] V. M. Robbins, S. C. Smith, and G. E. Stillman, "Impact ionization in $\mathrm{Al}_{\mathrm{x}} \mathrm{Ga}_{1-\mathrm{x}}$ As for $\mathrm{x}=0-0.4$," Appl. Phys. Lett., vol. 52, no. 4, pp. 296-298, Jan. 1988.

[88] S. A. Plimmer, J. P. R. David, R. Grey, and G. J. Rees, "Avalanche multiplication in $\mathrm{Al}_{\mathrm{x}} \mathrm{Ga}_{1-\mathrm{x}} \mathrm{As}(\mathrm{x}=0-0.6)$," IEEE Trans. Electron Devices, vol. 47, no. 5, pp. 1089-1097, May 2000.

[89] B. K. Ng, J. P. R. David, S. A. Plimmer, M. Hopkinson, R. C. Tozer, and G. J. Rees, "Impact ionization coefficients of $\mathrm{Al}_{0.8} \mathrm{Ga}_{0.2} \mathrm{As}$," Appl. Phys. Lett., vol. 77, no. 26, pp. 4374-4376, Dec. 2000.

[90] X. G. Zheng, X. Sun, S. Wang, P. Yuan, G. S. Kinsey, A. L. Holmes, Jr., B. G. Streetman, and J. C. Campbell, "Multiplication noise of $\mathrm{Al}_{\mathrm{x}} \mathrm{Ga}_{1-\mathrm{x}} \mathrm{As}$ avalanche photodiodes with high $\mathrm{Al}$ concentration and thin multiplication region," Appl. Phys. Lett., vol. 78, no. 24, pp. 3833-3835, Jun. 2001.

[91] X. G. Zheng, P. Yuan, X. Sun, G. S. Kinsey, A. L. Holmes, B. G. Streetman, and J. C. Campbell, "Temperature dependence of the ionization coefficients of $\mathrm{Al}_{\mathrm{x}} \mathrm{Ga}_{1-\mathrm{x}} \mathrm{As}$," IEEE J. Quantum Electron., vol. 36 , no. 10 , pp. 1168-1173, Oct. 2000.

[92] G. S. Kinsey, D. W. Gotthold, A. L. Holmes, Jr., and J. C. Campbell, "GaNAs resonant-cavity avalanche photodiode operating at $1.064 \mu \mathrm{m}$," Appl. Phys. Lett., vol. 77, no. 10, pp. 1543-1544, Sep. 2000.

[93] P. Yuan, S. Wang, X. Sun, X. G. Zheng, A. L. Holmes, Jr., and J. C. Campbell, "Avalanche photodiodes with an impact-ionizationengineered multiplication region," IEEE Photon. Technol. Lett., vol. 12, no. 10 , pp. $1370-1372$, Oct. 2000.

[94] O.-H. Kwon, M. M. Hayat, S. Wang, J. C. Campbell, A. L. Holmes, Jr., B. E. A. Saleh, and M. C. Teich, "Optimal excess noise reduction in thin heterojunction $\mathrm{Al}_{0.6} \mathrm{Ga}_{0.4} \mathrm{As}$-GaAs avalanche photodiodes," IEEE J. Quantum Electron., vol. 39, no. 10, pp. 1287-1296, Oct. 2003.

[95] C. Groves, C. K. Chia, R. C. Tozer, J. P. R. David, and G. J. Rees, "Avalanche noise characteristics of single $\mathrm{Al}_{\mathrm{x}} \mathrm{Ga}_{1-\mathrm{x}} \mathrm{As}(0.3<\times<$ 0.6)-GaAs heterojunction APDs," IEEE J. Quantum Electron., vol. 41, no. 1, pp. 70-75, Jan. 2005.

[96] S. Wang, R. Sidhu, X. G. Zheng, X. Li, X. Sun, A. L. Holmes, Jr., and J. C. Campbell, "Low-noise avalanche photodiodes with graded impactionization-engineered multiplication region," IEEE Photon. Technol. Lett., vol. 13, no. 12, pp. 1346-1348, Dec. 2001.

[97] S. Wang, F. Ma, X. Li, R. Sidhu, X. G. Zheng, X. Sun, A. L. Holmes, Jr., and J. C. Campbell, "Ultra-low noise avalanche photodiodes with a "centered-well" multiplication region," IEEE J. Quantum Electron., vol. 39, no. 2, pp. 375-378, Feb. 2003.

[98] M. M. Hayat, O.-H. Kwon, S. Wang, J. C. Campbell, B. E. A. Saleh, and M. C. Teich, "Boundary effects on multiplication noise in thin heterostructure avalanche photodiodes: Theory and experiment," IEEE Trans. Electron Devices, vol. 49, no. 12, pp. 2114-2123, Dec. 2002.

[99] S. Wang, J. B. Hurst, F. Ma, R. Sidhu, X. Sun, X. G. Zheng, A. L. Holmes, Jr., J. C. Campbell, A. Huntington, and L. A. Coldren, "Low-noise impact-ionization-engineered avalanche photodiodes grown on InP substrates," IEEE Photon. Technol. Lett., vol. 14, no. 12, pp. 1722-1724, Dec. 2002.

[100] N. Duan, S. Wang, F. Ma, N. Li, J. C. Campbell, C. Wang, and L. A. Coldren, "High-speed and low-noise SACM avalanche photodiodes with an impact-ionization engineered multiplication region," IEEE Photon. Technol. Lett., vol. 17, no. 8, pp. 1719-1721, Aug. 2005.

[101] F. Capasso, W. T. Tsang, A. L. Hutchinson, and G. F. Williams, "Enhancement of electron impact ionization in a superlattice: A new avalanche photodiode with a large ionization rate ratio," Appl. Phys. Lett., vol. 40, no. 1, pp. 38-40, Jan. 1982.

[102] R. Chin, N. Holonyak, Jr., G. E. Stillman, J. Y. Tang, and K. Hess, "Impact ionization in multilayered heterojunction structures," Electron. Lett., vol. 16, no. 12, pp. 467-469, Jun. 1980.

[103] M. M. Hayat, O.-H. Kwon, S. Wang, J. C. Campbell, B. E. A. Saleh, and M. C. Teich, "Boundary effects on multiplication noise in thin heterostructure avalanche photodiodes," IEEE Trans. Electron Devices, vol. 49, no. 12, pp. 2114-2123, Dec. 2002.

[104] K. Kato, S. Hata, K. Kawano, J.-I. Yoshida, and A. Kozen, "A highefficiency $50 \mathrm{GHz}$ InGaAs multimode waveguide photodetector," IEEE J. Quantum Electron., vol. 28, no. 12, pp. 2728-2735, Dec. 1992.

[105] F. Xia, J. K. Thomson, M. R. Gokhale, P. V. Studenkov, J. Wei, W. Lin, and S. R. Forrest, "An asymmetric twin-waveguide highbandwidth photodiode using a lateral taper coupler," IEEE Photon. Technol. Lett., vol. 13, no. 8, pp. 845-847, Aug. 2001.

[106] A. Umbach, "High-speed integrated photodetectors for $40 \mathrm{~Gb} / \mathrm{s}$ applications," Proc. SPIE, vol. 5246, no. 1, pp. 434-442, 2004.

[107] S. Demiguel, L. Giraudet, L. Joulaud, J. Decobert, F. Blache, V. Coupé, F. Jorge, P. Pagnod-Rossiaux, E. Boucherez, M. Achouche, and F. Devaux, "Evanescently coupled photodiodes integrating a double stage taper for $40 \mathrm{~Gb} / \mathrm{s}$ applications - Compared performance with side-illuminated photodiodes," J. Lightw. Technol., vol. 20, no. 12, pp. 2004-2014, Dec. 2002.

[108] T. Takeuchi, T. Nakata, K. Makita, and M. Yamaguchi, "High-speed, high-power and high-efficiency photodiodes with evanescently coupled graded-index waveguide," Electron. Lett., vol. 36, no. 11, pp. 972-973, Mar. 2000.

[109] C. Cohen-Jonathan, L. Giraudet, A. Bonzo, and J. P. Praseuth, "Waveguide AlInAs/GaAlInAs avalanche photodiode with a gainbandwidth product over $160 \mathrm{GHz}$," Electron. Lett., vol. 33, no. 17, pp. 1492-1493, Aug. 1997. 
[110] T. Nakata, G. Takeuchi, I. Watanabe, K. Makita, and T. Torikai, “ $10 \mathrm{~Gb} / \mathrm{s}$ high sensitivity, low-voltage-operation avalanche photodiodes with thin InAlAs multiplication layer and waveguide structure," Electron. Lett., vol. 36, no. 24, pp. 2033-2034, Nov. 2000.

[111] T. Nakata, T. Takeuchi, K. Maliita, Y. Amamiya, T. Kalo, Y. Suzuki, and T. Torikai, "High-sensitivity $40-\mathrm{Gb} / \mathrm{s}$ receiver with a wideband InAlAs waveguide avalanche photodiode," presented at the Eur. Conf. Optical Commun., Copenhagen, Denmark, 2002, Paper 10.5.1.

[112] K. Shiba, T. Nakata, T. Takeuchi, Y. Watanabe, S. Wada, and T. Torikai, "High sensitivity asymmetric waveguide APD with over-30 dBm at $10 \mathrm{~Gb} / \mathrm{s}$," presented at the Eur. Conf. Optical Commun., Stockholm, Sweden, 2004, Paper Mo4.4.3.

[113] G. S. Kinsey, J. C. Campbell, and A. G. Dentai, "Waveguide avalanche photodiode operating at $1.55 \mu \mathrm{m}$ with a gain-bandwidth product of 320 GHz," IEEE Photon. Technol. Lett., vol. 13, no. 8, pp. 842-844, Aug. 2001.

[114] T. Torikai, T. Nakata, T. Kato, and V. Makita, "40-Gbps waveguide avalanche photodiodes," presented at the Optical Fiber Commun. Conf. Tech. Dig., vol. 5, Anaheim, CA, 2005, Paper OFM3. (IEEE Cat. 05CH37672).

[115] J. Wei, F. Xia, and S. R. Forrest, "A high-responsivity high-bandwidth asymmetric twin-waveguide coupled InGaAs-InP-InAlAs avalanche photodiode," IEEE Photon. Technol. Lett., vol. 14, no. 11, pp. 15901592, Nov. 2002

[116] S. Demiguel, X.-G. Zheng, N. Li, X. Li, J. C. Campbell, J. Decobert, N. Tscherptner, and A. Anselm, "High-responsivity and high-speed evanescently-coupled avalanche photodiodes," Electron. Lett., vol. 39, no. 25 , pp. $1848-1849,2003$.

[117] W. P. Risk and D. S. Bethune, "Quantum cryptography," Opt. Photon. News, vol. 13, no. 7, pp. 26-32, 2002.

[118] S. Cova, M. Ghioni, A. Lotito, I. Rech, and F. Zappa, "Evolution and prospects for single-photon avalanche diodes and quenching circuits," J. Mod. Opt., vol. 51, no. 9/10, pp. 1267-1288, 2004.

[119] K. K. Forsyth and J. C. Dries, "Variations in the photon-counting performance of InGaAs/InP avalanche photodiodes," in Proc. IEEE LEOS Аnпu. Conf., 2003, vol. 2, p. 777.

[120] K. A. McIntosh, J. P. Donnelly, D. C. Oakley, A. Napoleon, S. D. Calawa, L. J. Mahoney, K. M. Molvar, E. K. Duerr, S. H. Groves, and D. C. Shaver, "InGaAsP/InP avalanche photodiodes for photon counting at $1.06 \mu \mathrm{m}, "$ Appl. Phys. Lett., vol. 81, no. 14, pp. 2505-2507, Sep. 2002.
[121] A. Tosi, S. Cova, F. Zappa, M. A. Itzler, and R. Ben-Michael, "InGaAs/ InP single photon avalanche diode design and characterization," in Proc. 36th Solid-State Device Res. Conf., Montreux, Switzerland, 2006, pp. 335-338. (IEEE Cat. No. 06EX1346).

[122] M. Liu, X. Bai, C. Hu, X. Guo, J. C. Campbell, X. Zheng, Z. Pan, and M. M. Toshima, "Low dark count rate and high single photon detection efficiency avalanche photodiode in Geiger-mode operation," presented at the 64th Device Research Conf., University Park, PA, Jun. 2006, Paper II.A-4.

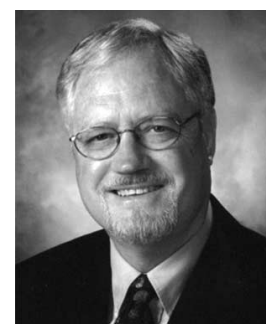

Joe C. Campbell (S'73-M'74-SM'88-F'90) received the B.S. degree from University of Texas at Austin in 1969 and the M.S. and Ph.D. degrees from University of Illinois at Urbana-Champaign in 1971 and 1973, respectively, all in physics.

From 1974 to 1976, he was employed with Texas Instruments, where he worked on integrated optics. In 1976, he joined the staff of AT\&T Bell Laboratories, Holmdel, NJ. With Crawford Hill Laboratory, AT\&T, he worked on a variety of optoelectronic devices, including semiconductor lasers, optical modulators, waveguide switches, photonic integrated circuits, and photodetectors with emphasis on high-speed avalanche photodiodes for high-bit-rate lightwave systems. In January 1989, he joined the faculty of University of Texas as Professor of electrical and computer engineering and Cockrell Family Regents Chair in engineering. In January 2006, he became a member of the faculty of University of Virginia, Charlottesville, as the Lucian Carr, III Chair of electrical engineering and applied science. His research has focused on the optoelectronic components that are used to generate, modulate, and detect the optical signals Currently, he is actively involved in single-photon-counting avalanche photodiodes, Si-based optoelectronics, high-speed low-noise avalanche photodiodes, ultraviolet photodetectors, and quantum-dot IR imaging. To date, he has coauthored six book chapters, 320 articles for refereed technical journals, and more than 200 conference presentations.

Prof. Campbell is a member of the National Academy of Engineering, a Fellow of the Optical Society of America, and a Fellow of the American Physical Society. 